\title{
A Facile Strategy to Achieve Large Triplet Gap Based on Excited-State Aromaticity- tunable Five-memebered Ring
}

\author{
Qi Sun ${ }^{1}$, Yuanyuan $\mathrm{Cui}^{3}$, Yishi $\mathrm{Wu}^{4}$, Can $\mathrm{Gao}^{4}$, Qi Ou${ }^{1}$, Deping $\mathrm{Hu}^{1}$, Lu Wang ${ }^{1}$, Yue Wang ${ }^{3}$, \\ Huanli Dong ${ }^{4}$, Qian Peng ${ }^{2,4 *}$, and Zhigang Shuai ${ }^{1 *}$ \\ ${ }^{1}$ MOE Key Laboratory of Organic Optoelectronics and Molecular Engineering, Department of Chemistry Tsinghua University, Beijing 100084, P. $R$. \\ China \\ ${ }^{2}$ School of Chemical Sciences, University of Chinese Academy of Sciences, Beijing, 100049, China. \\ ${ }^{3}$ State Key Laboratory of Supramolecular Structure and Materials, College of Chemistry, Jilin University, Changchun 130012, P. R. China \\ ${ }^{4}$ Beijing National Laboratory for Molecular Sciences, Institute of chemistry, Chinese Academy of Sciences, Beijing 100190, P. R. China \\ *Corresponding authors. Email addresses: qpeng@iccas.ac.cn; zgshuai@tsinghua.edu.cn.
}

Keywords: triplet energy gap, quantum chemistry computation, five-membered rings, ultrafast spectroscopy, singlet fission, hot exciton

\begin{abstract}
Organic molecules with large triplet gap between $\mathrm{T}_{1}$ and $\mathrm{T}_{2}\left(\Delta E_{\mathrm{T}_{1} \mathrm{~T}_{2}}\right)$ can be applied in hot exciton mechanism and singlet fission to beat the spin statistics limit in optoelectronic devices. Based on theoretical calculations, we propose a molecule design strategy to achieve large $\Delta E_{\mathrm{T}_{1} \mathrm{~T}_{2}}$ by manipulating the aromaticity and the transition properties of the low-lying excited states. For the first time, partially conjugated five-membered rings are found to naturally have low $E\left(\mathrm{~T}_{1}\right)$ owing to high aromaticity obeying Baird's Rule. By applying such ring as a bridge and linking various

donor and acceptor moieties to control the $S_{1}$ and $T_{2}$ states, we have designed numbers of derivatives with tunable emission color, all possessing large $\Delta E_{\mathrm{T}_{1} \mathrm{~T}_{2}}$ and satisfying $E\left(\mathrm{~T}_{2}\right)>E\left(\mathrm{~S}_{1}\right) \geq 2 E\left(\mathrm{~T}_{1}\right)$. The ultrafast spectroscopy and sensitization measurements for one designed molecule (TPA-DBPrz) confirm $\Delta E_{\mathrm{T}_{1} \mathrm{~T}_{2}}$ to be $820 \mathrm{~nm}$, in excellent agreement with our calculations. This design strategy provides a novel route to develop high-efficiency optoelectronic materials.
\end{abstract}

\section{Introduction}

Organic light-emitting diodes (OLEDs) have been successfully commercialized on displays and solid-phase lighting due to their advantages. ${ }^{[1]}$ There has been a long-standing challenge to beat $25 \%$ statistical limit ${ }^{[2]}$ in the electroluminescence devices. Recently, nearly $100 \%$ IQE has been obtained in the thermally-activated delayed fluorescence (TADF) materials for electrofluorescence. ${ }^{[3]}$ For TADF materials, efficient reverse intersystem crossing (RISC) is essential to convert triplet states to singlet manifold for fluorescence, which usually requires a 
significantly small singlet-triplet energy gap $\left(\Delta E_{\mathrm{ST}}\right) .{ }^{[3 \mathrm{a}]}$ It is well known that such small $\Delta E_{\mathrm{ST}}$ can be generated by separating the highest occupied molecular orbital (HOMO) and lowest unoccupied molecular orbital (LUMO) in space, which concurrently leads to very weak oscillator strength, quite small emissive cross section and considerably long fluorescence lifetime. ${ }^{[3 a, 4]}$ The hybrid locally-excited charge transfer (HLCT) materials based on the hot exciton mechanism put forth by Ma and Yang are expected to make up for the deficiency, because more local excitation (LE) feature produces larger oscillator strength for fluorescence and RISC between higher excited singlet and triplet manifolds is more efficient without serious time delay. ${ }^{[5]}$ However, there is a very harsh condition for organic compounds to possess a large $\Delta E_{\mathrm{T}_{1} \mathrm{~T}_{2}}$ to suppress the nonradiative internal conversion from $\mathrm{T}_{2}$ to $\mathrm{T}_{1}$.

Very recently, the singlet fission (SF) materials are promising candidates for organic photovoltaics and electroluminescence because two low-energy triplet excited states $\left(\mathrm{T}_{1}\right)$ are generated from one high-energy singlet excited state $\left(S_{1}\right)$, leading to overcoming of the single junction limit in solar cells ${ }^{[6]}$ and the $25 \%$ statistical limit in OLED ${ }^{[7]}$. An efficient SF process basically requires the excited energy of $S_{1}$ larger than twice the excited energy of $T_{1}$, $E\left(\mathrm{~S}_{1}\right) \geq 2 E\left(\mathrm{~T}_{1}\right) \cdot{ }^{[8]}$ In addition, the other energy condition of $E\left(\mathrm{~T}_{2}\right)>E\left(\mathrm{~S}_{1}\right) \geq 2 E\left(\mathrm{~T}_{1}\right)$ should also be satisfied to avoid the intersystem crossing (ISC) from $S_{1}$ to $T_{2}$ and the recombination of $T_{1}$ excitons. ${ }^{[9]}$ Overall, the SF and HLCT materials have similar energy requirements (see Figure 1), i.e., ultralow $E\left(\mathrm{~T}_{1}\right)$ level and large $\Delta E_{\mathrm{T}_{1} \mathrm{~T}_{2}}$. However, it is a formidable challenge to design molecules with either low $E\left(\mathrm{~T}_{1}\right)$ or large $\Delta E_{\mathrm{T}_{1} \mathrm{~T}_{2}}$, let alone both.

In this work, we first demonstrate that some triplet-stabilized five-membered rings (i.e., pyrazoline) naturally have low $E\left(\mathrm{~T}_{1}\right)$ owing to high aromaticity in $\mathrm{T}_{1}$ obeying Baird's Rule ${ }^{[10]}$ and large $\Delta E_{\mathrm{T}_{1} \mathrm{~T}_{2}}$ due to different transition property. A series of donor-bridge-acceptor (D-BA) systems are then designed based on pyrazoline ring as a bridge via introducing different donor or acceptor moieties (see Scheme 1). For the constructed pyrazoline derivatives, the low 
$E\left(\mathrm{~T}_{1}\right)$ is consistently maintained because the transition density of $\mathrm{T}_{1}$ is localized in pyrazoline ring and the high $E\left(\mathrm{~T}_{2}\right)$ is generated via a transition over substituted donors or acceptors, which results in a large $\Delta E_{\mathrm{T}_{1} \mathrm{~T}_{2}}$. With that, a novel series of full-color emitters with large $\Delta E_{\mathrm{T}_{1} \mathrm{~T}_{2}}$ and low $E\left(\mathrm{~T}_{1}\right)$ are predicted through theoretical calculations and proved by transient absorption spectroscopy spectra of TPA-DBPrz, which, to the best of our knowledge, has not been previously reported.

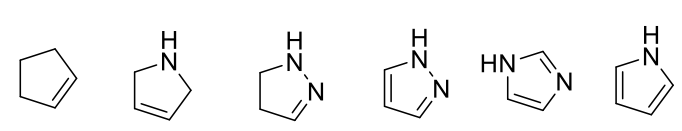
cyclopentene 3-pyrroline pyrazoline pyrazole imidazole pyrrole



pyrazolinea

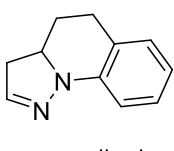

pyrazolineb

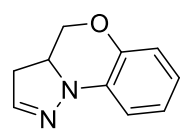

pyrazolinec
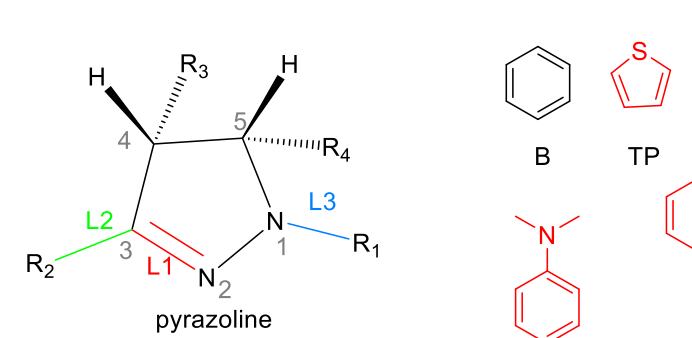<smiles>c1ccc2c(c1)[nH]c1ccccc12</smiles><smiles>c1ccc2c(c1)Nc1ccccc1S2</smiles>
PTZ<smiles>c1ccc2c(c1)Nc1ccccc1N2</smiles>

B TP $\mathrm{Cz}$

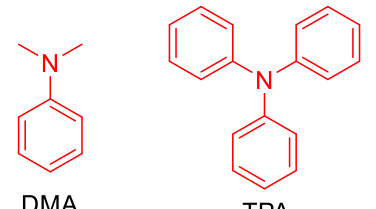

DMA

TPA
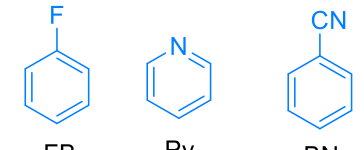

BN

\begin{tabular}{|c|c|c|c|c|c|c|c|c|c|c|c|c|c|c|}
\hline Compound & $\mathrm{R}_{1}$ & $\mathrm{R}_{2}$ & $\mathrm{R}_{3}$ & $\mathrm{R}_{4}$ & Compound & $\mathrm{R}_{1}$ & $\mathrm{R}_{2}$ & $\mathrm{R}_{3}$ & $\mathrm{R}_{4}$ & Compound & $\mathrm{R}_{1}$ & $\mathrm{R}_{2}$ & $\mathrm{R}_{3}$ & $\mathrm{R}_{4}$ \\
\hline 1 & B & FB & $\mathrm{H}$ & $\mathrm{H}$ & 10 & FB & $\mathrm{B}$ & $\mathrm{H}$ & $\mathrm{H}$ & 19 & B & FB & B & $\mathrm{H}$ \\
\hline 2 & TP & FB & $\mathrm{H}$ & $\mathrm{H}$ & 11 & $\mathrm{H}$ & B & $\mathrm{H}$ & FB & 20 & B & FB & DMA & $\mathrm{H}$ \\
\hline 3 & TP & Py & $\mathrm{H}$ & $\mathrm{H}$ & 12 & $\mathrm{H}$ & FB & $\mathrm{H}$ & B & 21 & B & FB & Py & $\mathrm{H}$ \\
\hline 4 & $\mathrm{Cz}$ & Py & $\mathrm{H}$ & $\mathrm{H}$ & 13 & $\mathrm{H}$ & FB & B & $\mathrm{H}$ & 22 & $B$ & FB & $\mathrm{H}$ & B \\
\hline 5 & $\mathrm{Cz}$ & $\mathrm{BN}$ & $\mathrm{H}$ & $\mathrm{H}$ & 14 & $\mathrm{H}$ & $B$ & FB & $\mathrm{H}$ & 23 & $B$ & FB & $\mathrm{H}$ & DMA \\
\hline 6 & PTZ & Py & $\mathrm{H}$ & $\mathrm{H}$ & 15 & FB & $\mathrm{H}$ & $B$ & $\mathrm{H}$ & 24 & $B$ & FB & $\mathrm{H}$ & Py \\
\hline 7 & PTZ & $\mathrm{BN}$ & $\mathrm{H}$ & $\mathrm{H}$ & 16 & $B$ & $\mathrm{H}$ & FB & $\mathrm{H}$ & TPA-DBPrz & B & B & $\mathrm{H}$ & TPA \\
\hline 8 & $\mathrm{PZ}$ & B & $\mathrm{H}$ & $\mathrm{H}$ & 17 & $B$ & $\mathrm{H}$ & $\mathrm{H}$ & FB & & & & & \\
\hline 9 & $\mathrm{PZ}$ & $\mathrm{BN}$ & $\mathrm{H}$ & $\mathrm{H}$ & 18 & FB & $\mathrm{H}$ & $\mathrm{H}$ & B & & & & & \\
\hline
\end{tabular}

Scheme 1. Chemical structures of five-membered rings and constructed molecules in this work (red: donor; blue: acceptor). 
Singlet fission process

$E\left(\mathrm{~T}_{2}\right)>E\left(\mathrm{~S}_{1}\right) \geq 2 E\left(\mathrm{~T}_{1}\right)$

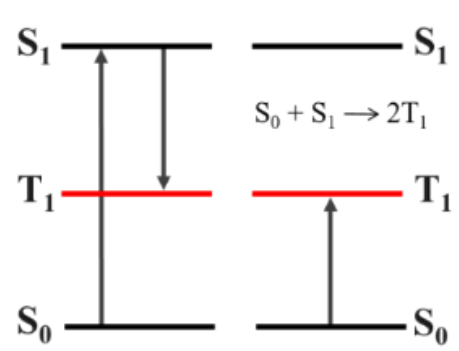

Hot exciton process

$E\left(\mathrm{~T}_{2}\right)>>E\left(\mathrm{~T}_{1}\right)$

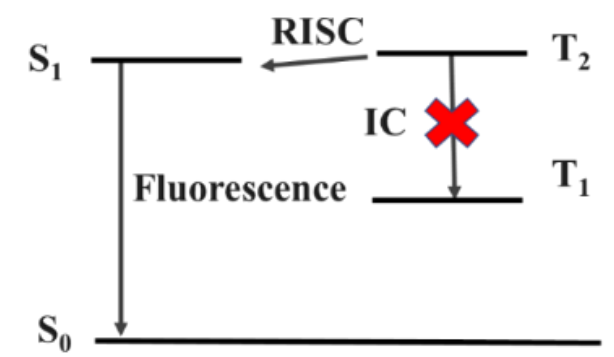

Figure 1. Schematic diagram of energy levels for the SF and HLCT materials.

\section{Results and Discussion}

\subsection{Five-membered rings with low $E\left(T_{1}\right)$ and large $\Delta E_{\mathrm{T}_{1} \mathrm{~T}_{2}}$.}

The conjugated five-membered rings are frequently used as fundamental units in luminous molecules, such as cyclopentene, 3-pyrroline, pyrazoline, pyrazole, imidazole and pyrrole as shown in Scheme 1. The effects of molecular conjugation on the emissive spectra and efficiencies from $S_{1}$ have been widely investigated in organic systems. ${ }^{[11]}$ However, the roles of molecular conjugation in triplet states have rarely been explored. We here systematically investigate low-lying excited triplet and singlet states of five-membered rings with different degree of conjugation, including olefinic rings (cyclopentene), antiaromatic rings (3-pyrroline and pyrazoline) and aromatic rings (pyrazole, imidazole and pyrrole).

We optimize the geometrical structures via SA4-CASSCF/cc-PVTZ with active space (10e, 10o) and calculate the electronic structures of the low-lying excited triplet and singlet states of these five-numbered rings via MS4-CASPT2/cc-PVTZ, and the results are shown in Figure 2 and Table 1. It is seen in Figure 2a that cyclopentene, 3-pyrroline and pyrazoline are partially conjugated with transition densities mainly localized on double bond and lone-pair electrons, while pyrazole, imidazole and pyrrole are fully conjugated with transition density delocalized over the whole rings. Furthermore, it is found from Table 1 that the partly conjugated 
cyclopentene, 3-pyrroline and pyrazoline rings have low $E\left(\mathrm{~T}_{1}\right)$, which naturally meet the energy condition of $E\left(\mathrm{~T}_{1}\right)<<E\left(\mathrm{~T}_{2}\right)$ as required for HLCT materials and $2 E\left(\mathrm{~T}_{1}\right) \leq E\left(\mathrm{~S}_{1}\right)<E\left(\mathrm{~T}_{2}\right)$ as needed for SF materials; while the fully conjugated pyrazole, imidazole and pyrrole rings possess high $E\left(\mathrm{~T}_{1}\right)$ and relatively small $\Delta E_{\mathrm{T}_{1} \mathrm{~T}_{2}}$. Upon excitation, the double bonds are elongated to a greater extent in cyclopentene $(0.130 \AA)$, 3-pyrroline $(0.158 \AA)$ and pyrazoline $(0.184 \AA)$ than those (ca. $0.100 \AA$ ) in pyrazole, imidazole and pyrrole as shown in Figure $2 \mathbf{b}$ and S1, which largely weaken the coupling between the two p orbitals of the former, leading to low $E\left(\mathrm{~T}_{1}\right)$. These results are also consistent with Baird's Rule, in which the aromaticity is always changed upon triplet excitation and the aromatic triplet states are more stable with lower energy. ${ }^{[10,12]}$ For example, pyrazoline is a three-center four-electron $\left(\pi_{3}^{4}\right)$ five-membered ring which appear aromaticity in $\mathrm{T}_{1}$. The anisotropy of the induced current density ${ }^{[13]}$ (AICD) which can character the molecular aromaticity is calculated and plotted in Figure 2c. The clockwise ring currents in Figure 2c of cyclopentene, 3-pyrroline and pyrazoline rings indicate them to be aromatic while the anticlockwise ring currents in pyrazole, imidazole and pyrrole prove them to be antiaromatic in $\mathrm{T}_{1}$. Thus, according to Baird's Rule, cyclopentene, 3-pyrroline and pyrazoline retain stabilized $\mathrm{T}_{1}$ states with ultralow energy. Furthermore, the orbitals are energetically wellseparated in these rings as shown in Figure 2d, especially, the energy gap between HOMO and HOMO-1 is very large. The $\mathrm{T}_{1}$ states are dominated by the transition from HOMO to LUMO while the $\mathrm{T}_{2}$ states stem from the ones from deeper occupied orbitals to LUMO or higher unoccupied orbitals, which results in large $\Delta E_{\mathrm{T}_{1} \mathrm{~T}_{2}}$. All these results indicate cyclopentene, 3pyrroline and pyrazoline are expected to be good triplet-stabilized candidates for ultralow $E\left(\mathrm{~T}_{1}\right)$ and ultra-large $\Delta E_{\mathrm{T}_{1} \mathrm{~T}_{2}}$. The similar conclusion can be obtained by the TDA-DFT approach as shown in supporting information (SI). 
(a)



(b)

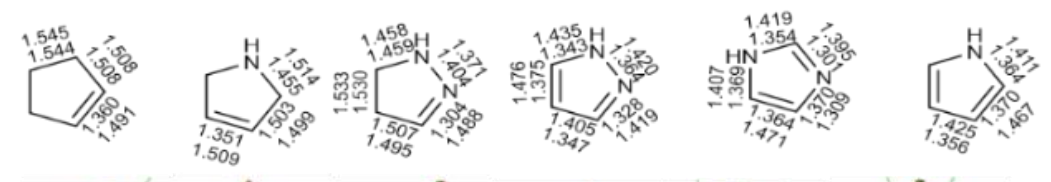

(c)

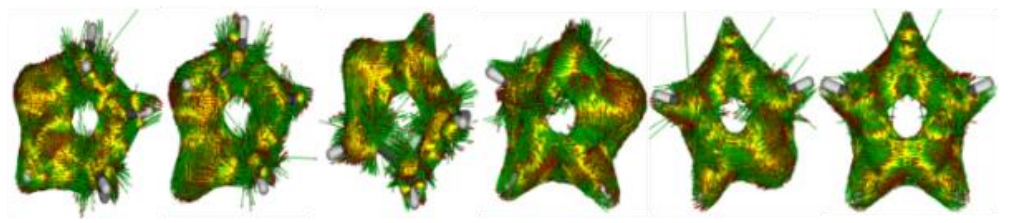

cyclopentene 3-pyrroline pyrazoline pyrazole imidazole pyrrole

(d)

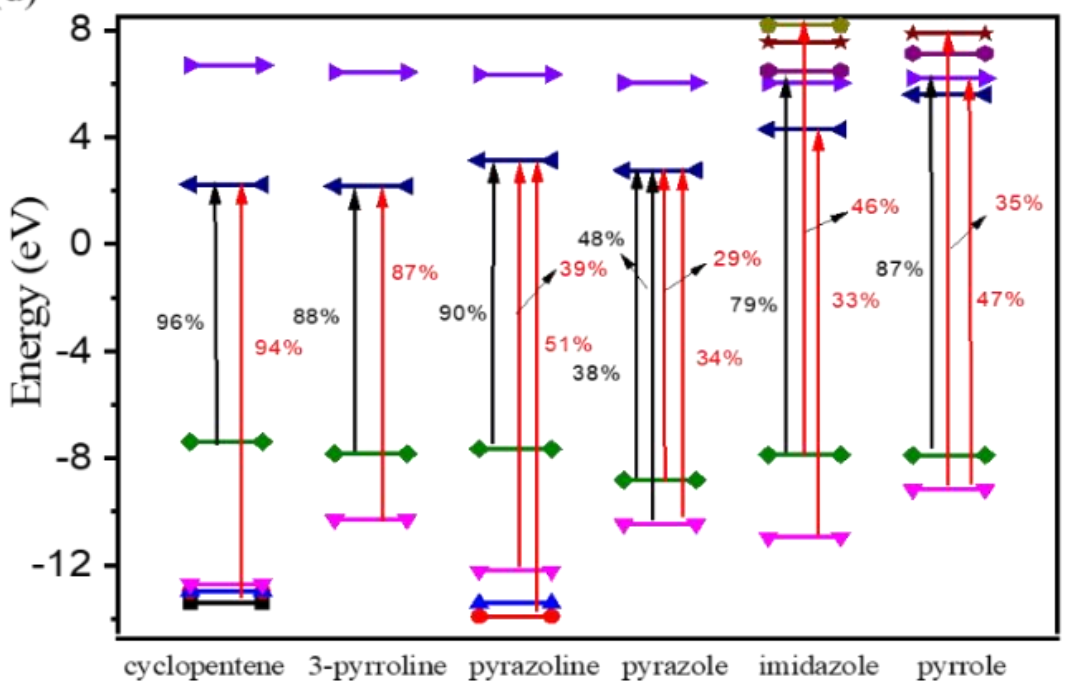

Figure 2. (a) Nature transition orbitals (NTOs) of $\mathrm{T}_{1}$ at $\mathrm{T}_{1}$-geometry; (b) Optimized bond lengths (Inside: S0-geometry; Outside: $\mathrm{T}_{1}$-geometry); (c) AICD plots of six five-numbered rings in $\mathrm{T}_{1}$ state in which the induced current density vectors denoted by the arrows; and (d) frontier orbitals energies and transitions of $\mathrm{T}_{1}$ (black) and $\mathrm{T}_{2}$ (red) states.

Table 1. Vertical excitation energies (Unit: $\mathrm{eV}$ ) of six five-numbered rings at $\mathrm{T}_{1}$-geometry.

\begin{tabular}{cccccc}
\hline Compound & $E\left(\mathrm{~T}_{1}\right)$ & $E\left(\mathrm{~T}_{2}\right)$ & $E\left(\mathrm{~S}_{1}\right)$ & $2 E\left(\mathrm{~T}_{1}\right)$ & $\Delta E_{\mathrm{T}_{1} \mathrm{~T}_{2}}$ \\
\hline cyclopentene & 1.01 & 6.04 & 3.77 & 2.02 & 5.03 \\
3-pyrroline & 1.26 & 4.09 & 3.56 & 2.52 & 2.83 \\
pyrazoline & 1.54 & 4.68 & 3.55 & 3.08 & 3.14 \\
pyrazole & 2.84 & 4.43 & 4.97 & 5.68 & 1.59 \\
imidazole & 3.44 & 5.10 & 5.44 & 6.88 & 1.66 \\
pyrrole & 3.35 & 4.84 & 5.34 & 6.70 & 1.49 \\
\hline
\end{tabular}

We further calculate the low-lying excited states of the extended rings based on pyrazoline at TDA/LC- $\omega$ PBE*/6-31G(d) level. They all exhibit ultralow $E\left(\mathrm{~T}_{1}\right)$ compared with $E\left(\mathrm{~S}_{1}\right)$ (Table 
$\mathrm{S} 3$ ) because the $\mathrm{T}_{1}$ mainly originates from the pyrazoline ring (Figure $\mathrm{S} 3 \mathrm{a}$ ), while $E\left(\mathrm{~T}_{2}\right)$ is significantly changed by the introduced chemical groups. These results further demonstrate the partly conjugated rings can serve as triplet-stabilized moieties for the HLCT and SF materials.

\subsection{Construction of pyrazoline derivatives with low $E\left(T_{1}\right)$ and large $\Delta E_{\mathrm{T}_{1} \mathrm{~T}_{2}}$.}

Pyrazoline derivatives have been investigated as hole-transport materials ${ }^{[14]}$, fluorescent sensor $^{[15]}$ and medicine ${ }^{[16]}$ owing to high stability and wonderful photophysical properties. Hence, in this work, pyrazoline ring is used as a bridge (B) to construct 25 compounds by introducing different donor (D) and acceptor (A) groups, namely, D-B-A type (see Scheme 1). The electron-withdrawing ability of the acceptors becomes stronger from FB, Py to BN owing to lower LUMO energies, and the electron-donating ability of the donors becomes stronger from TP, Cz, PTZ to PZ due to higher HOMO energies (Table S4).

Compounds 1-9 with different D or A at the same substituted 1- and 3-positions all possess with nearly coplanar conformations with high rigidity. Upon excitation, significant modifications occur on three bond lengths rather than angles and dihedral angles, as seen in Table S5. These three bond lengths are $\mathrm{C}=\mathrm{N}$ in pyrazoline ring $\left(\mathrm{L}_{1}\right)$, the bond linking $\mathrm{B}$ and $\mathrm{A}\left(\mathrm{L}_{2}\right)$ and the bond linking B and D $\left(\mathrm{L}_{3}\right)$, respectively, as illustrated in Scheme 1. From $\mathrm{S}_{0}$-geometry to $\mathrm{T}_{1}$ geometry, $\mathrm{L}_{1}$ is considerably elongated by $0.081-0.136 \AA$, which is similar to the change of single pyrazoline ring, while $\mathrm{L}_{2}$ and $\mathrm{L}_{3}$ are slightly shortened by $0.002-0.07 \AA$ as seen in Table S5. The hole-electron analyses are carried out to unravel the transition nature of the low-lying excited states, and the resultant hole-electron distribution heat maps and natural transition orbitals (NTOs) are plotted in Figure 3 and Figure S4, respectively. The hole-electron distribution heat map can intuitively characterize the contribution from each subgroup (i.e., B, $\mathrm{D}$ and $\mathrm{A})$ to the transition density of the molecule. ${ }^{[17]}$ Both of the hole-electron heat maps and NTOs indicate that $T_{1}$ of the molecules is a LE state originating from pyrazoline ring, which results in the fact that their $E\left(\mathrm{~T}_{1}\right)$ is very close to that of single pyrazoline ring, namely, ca. 1.50 
$\mathrm{eV}$, as shown in Figure 4a. Differently, $\mathrm{T}_{2}$ is a LE state mainly stemming from either acceptor or donor of the molecules, which have much wider energy-gap transitions than that of pyrazoline ring. Thus, $E\left(\mathrm{~T}_{1}\right)$ is much smaller than $E\left(\mathrm{~T}_{2}\right)$. By contrast, $\mathrm{S}_{1}$ acquires a slightly delocalized transition with partial CT character. The resultant $E\left(\mathrm{~S}_{1}\right)$ is smaller than $E\left(\mathrm{~T}_{2}\right)$ as seen in Figure 4a. Furthermore, the difference in the nature of electronic configuration between $\mathrm{T}_{2}$ and $\mathrm{S}_{1}$ states can give rise to large spin-orbit coupling (SOC), which facilitates the mutual conversion between them under the hot exciton mechanism. Overall, the nine compounds all meet the energy conditions of $E\left(\mathrm{~T}_{1}\right)<<E\left(\mathrm{~T}_{2}\right)$ and $2 E\left(\mathrm{~T}_{1}\right) \leq E\left(\mathrm{~S}_{1}\right)<E\left(\mathrm{~T}_{2}\right)$, indicating them to be good candidates for HLCT or SF molecules. In addition, while retaining large $\Delta E_{\mathrm{T}_{1} \mathrm{~T}_{2}}$, the emissive wavelengths vary in a wide visible region of $2.30 \sim 3.27 \mathrm{eV}$ owing to different $\mathrm{D}$ and $\mathrm{A}$ in these nine molecules (Table S6), which enriches the HLCT or SF molecules with multicolor light.

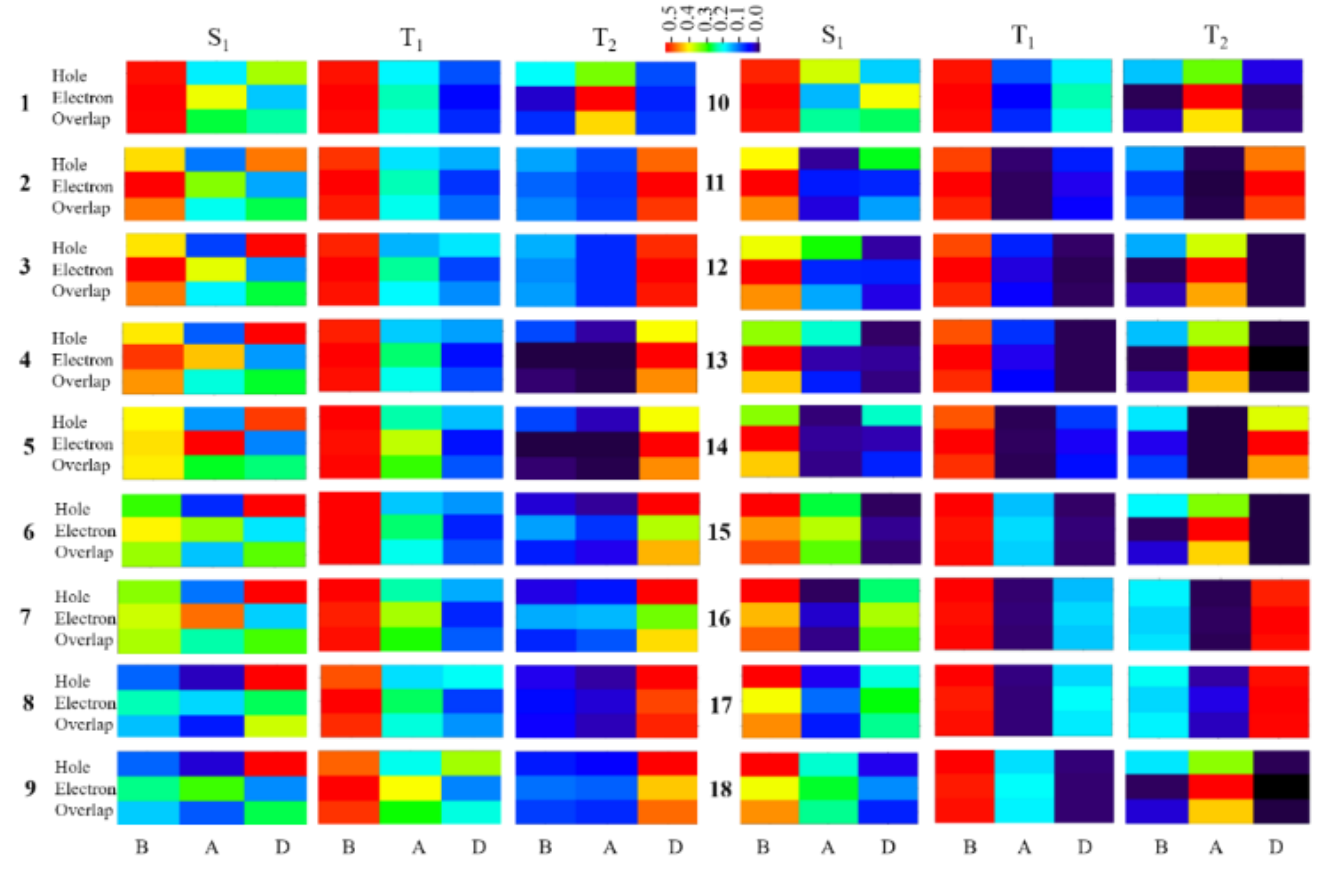

Figure 3. Hole-electron distribution heat maps of 1-18. 
Among the nine compounds, compound 1 has the largest $\Delta E_{\mathrm{T}_{1} \mathrm{~T}_{2}}(2.19 \mathrm{eV})$ with the substituents BF and B. Hence, we change the substituted position of BF and B (compounds 10-18 in Scheme 1) to investigate position dependence of the substituents on the properties of the low-lying excited states. It can be seen from Figure $4 \mathbf{b}$ that (i) the energy relationships of $E\left(\mathrm{~T}_{1}\right)<<E\left(\mathrm{~T}_{2}\right)$ are still maintained with $\Delta E_{\mathrm{T}_{1} \mathrm{~T}_{2}}$ larger than $1.91 \mathrm{eV}$, which is independent on the positions of $\mathrm{BF}$ and $\mathrm{B}$ in the pyrazoline ring; (ii) the $2 E\left(\mathrm{~T}_{1}\right) \leq E\left(\mathrm{~S}_{1}\right)<E\left(\mathrm{~T}_{2}\right)$ is well held except for 11 and 14 with $\mathrm{B}$ at the 3- site and BF at the 4- or 5- sites of pyrazoline ring; (iii) relative to compound 1 and 10, the $E\left(\mathrm{~S}_{1}\right)$ and $E\left(\mathrm{~T}_{2}\right)$ are raised while the $E\left(\mathrm{~T}_{1}\right)$ fluctuates between 1.30 and $1.71 \mathrm{eV}$ for compounds 11-18. Thus, it can be predicted that among these systems, compounds 12, 15 and 18 would be excellent HLCT materials because of large $\Delta E_{\mathrm{T}_{1} \mathrm{~T}_{2}}$ that blocks the internal conversion from $\mathrm{T}_{2}$ to $\mathrm{T}_{1}$ and small $\Delta E_{\mathrm{S}_{1} \mathrm{~T}_{2}}$ that facilitates the intersystem crossing from $\mathrm{T}_{2}$ to $\mathrm{S}_{1}$; and Compounds 10,16 and 17 would act as SF materials owing to not only $2 E\left(\mathrm{~T}_{1}\right) \leq E\left(\mathrm{~S}_{1}\right)$ but also large $\Delta E_{\mathrm{S}_{1} \mathrm{~T}_{2}}$. The reason of the ultralow $E\left(\mathrm{~T}_{1}\right)$ and large $\Delta E_{\mathrm{T}_{1} \mathrm{~T}_{2}}$ in 10-18 is the same with that in 1-9 (Figure 3 and Figure S4).

The effect of the number of substituents on the excited state property are further studied through adding donor or acceptor at 4- or 5-site of pyrazoline ring when B and BF are fixed at 1- and 3site, respectively (compounds 19-24 in Scheme 1), and the resultant excitation energies and NTOs are given in Table S6 and Figures 4c, S4. It can be seen that the $E\left(\mathrm{~S}_{1}\right), E\left(\mathrm{~T}_{1}\right), E\left(\mathrm{~T}_{2}\right)$ of these compounds 19-24 are all similar to those of compound $\mathbf{1}$, which suggests the substituents linked to the $\mathrm{sp}^{3}$ hybridized carbon atom of the pyrazoline $\left(\mathrm{R}_{3}\right.$ and $\left.\mathrm{R}_{4}\right)$ have no effect on the excited-state properties while the ones at the conjugated part of the pyrazoline ring play important roles. Therefore, it can be declared that the low-lying excited-state properties and emissive color can be tuned by changing $\mathrm{R}_{1}$ and $\mathrm{R}_{2}$ at 1 - and 3- sites of pyrazoline ring, and other physical properties such as crystallization ability, glass-transition temperature etc. can be 
controlled via adding $\mathrm{R}_{3}$ or $\mathrm{R}_{4}$ at 4- and 5-sites. Thus, excellent HLCT or SF materials can be properly designed for optoelectronic devices.
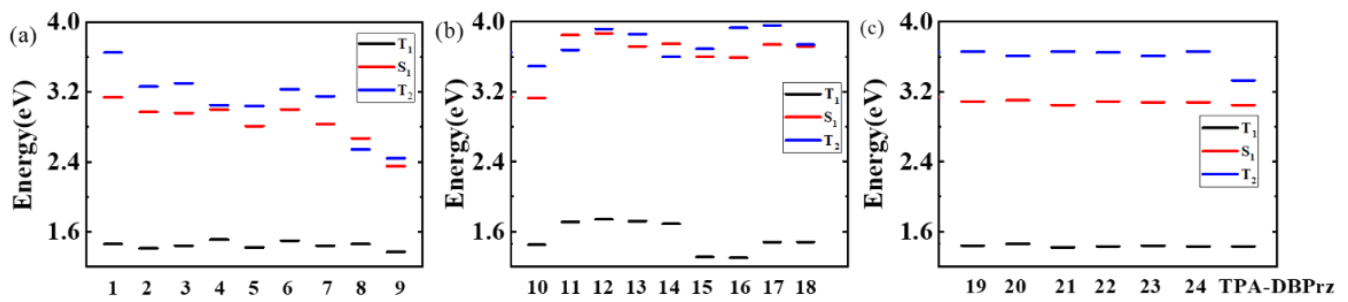

Figure 4. Excitation energies of the compounds at $\mathrm{T}_{1}$-geometry at TDA/LC- $\omega \mathrm{PBE} * / 6-31 \mathrm{G}(\mathrm{d})$ level.

\subsection{Experimental validation of theoretically designed TPA-DBPrz molecule.}

Keeping the above design strategy in mind, we build a compound named as TPA-DBPrz with $\mathrm{R}_{1}=\mathrm{B}, \mathrm{R}_{2}=\mathrm{B}, \mathrm{R}_{3}=\mathrm{H}$ and $\mathrm{R}_{4}=\mathrm{TPA}$, which has properly large molecular weight to meet the requirement for the application in optoelectronic devices. The low-lying excited states are calculated at MS4-CASPT2(8,8)/cc-PVDZ level and the results are given in Figure 5, including energy levels, transition properties and involved frontier orbitals. The $S_{1}$ state has a hybrid transition character with LE on pyrazoline and CT from 1-site phenyl to 3-site phenyl ring. The $\mathrm{T}_{1}$ state stems from LE on pyrazoline ring, as well as a marginal contribution from two phenyl rings. The $\mathrm{T}_{2}$ state comes from the electron transition on TPA moiety. The resultant $E\left(\mathrm{~S}_{1}\right), E\left(\mathrm{~T}_{2}\right)$ and $E\left(\mathrm{~T}_{1}\right)$ are $2.68,1.55$, and $3.23 \mathrm{eV}$ based on $\mathrm{T}_{1}$-goemetry, respectively, leading to large $\Delta E_{\mathrm{T}_{1} \mathrm{~T}_{2}}$ of $1.68 \mathrm{eV}$.

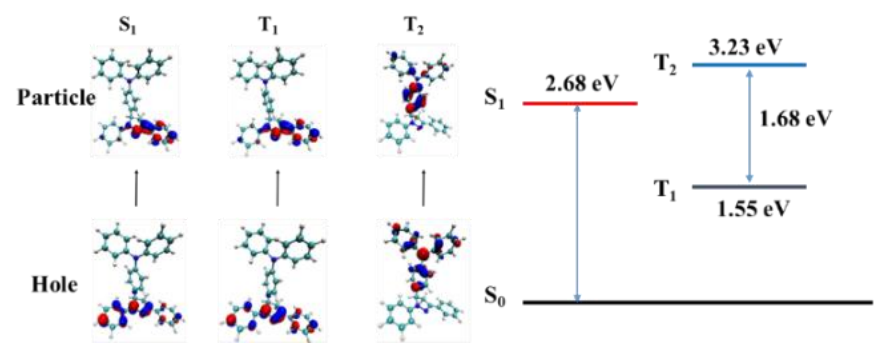

Figure 5. NTOs and energy levels of TPA-DBPrz based on $\mathrm{T}_{1}$-goemetry.

To confirm our theoretical predictions, we synthesized TPA-DBPrz compound and measured its photophysical properties. The synthetic route of TPA-DBPrz is shown in Scheme S1 and it 
is characterized and verified by ${ }^{1} \mathrm{H} \mathrm{NMR},{ }^{13} \mathrm{C} \mathrm{NMR}$, high resolution mass spectrometry and elemental analysis as given in SI. The ultraviolet-visible absorption and photoluminescence (PL) spectra of TPA-DBPrz in chloromethane (DCM) solution are plotted in Figure 6a. The PL shows a blue emission with a maximum peak at $453 \mathrm{~nm}$, very close to the theoretical value. The PL lifetime curve exhibits a single-exponential fluorescence decay process in DCM solution with and without degassed (Figure 6b). However, the excited-state lifetime in the former condition (5.58 ns) is slightly longer than that (4.61 ns) in the latter condition, confirming the generation of triplet state. These are similar to the typical HLCT behaviors. ${ }^{[18]}$ The photoluminescence quantum yield is $90 \%$ in the DCM solution indicating the highly efficient luminescence process. The femtosecond transient absorption spectroscopy (fs-TA) spectra of TPA-DBPrz in dichloromethane (DCM) is performed with excitation wavelength of 400 nm (see Figure 6c-d, S5) and it is found that there appear two types of features: one peak is near $577 \mathrm{~nm}$ in a short time, and the other is at $520 \mathrm{~nm}$ and $820 \mathrm{~nm}$ after ca. 1998.98 picoseconds (ps). Combining fs-TA spectra and the dynamic curve in Figure 6c-d and Figure $\mathrm{S} 5$, it is seen that (i) the excited state corresponding to $577 \mathrm{~nm}$ firstly appear and then quickly disappear, which can be attributed to the absorption from $\mathrm{S}_{1}$ state; (ii) the excited state corresponding to $520 \mathrm{~nm}$ and $820 \mathrm{~nm}$ is transferred from the $S_{1}$ state, which is hypothetically assigned to be the absorption from $T_{1}$ to $T_{n}$ state. In order to confirm the absorption of $T_{1}$, we further sensitize the $\mathrm{T}_{1}$ state of the TPA-DBPrz using a phosphorescence dye $\mathrm{Ru}(\mathrm{bpy})_{3} \mathrm{Cl}_{2}$ with a low $E\left(\mathrm{~T}_{1}\right)(2.1 \mathrm{eV}),{ }^{[19]}$ and measure the nanosecond transient absorption spectroscope (nsTA) of the sole $\mathrm{Ru}(\mathrm{bpy})_{3} \mathrm{Cl}_{2}$ and TPA-DBPrz\& $\mathrm{Ru}(\mathrm{bpy})_{3} \mathrm{Cl}_{2}$ in DCM, as provided in Figure 6ef and S6. It is seen that the sole $\mathrm{Ru}(\mathrm{bpy}){ }_{3} \mathrm{Cl}_{2}$ show no absorption band at $520 \mathrm{~nm}$ and $820 \mathrm{~nm}$


$820 \mathrm{~nm}(1.51 \mathrm{eV})$ and a very strong and long-lived (> $2000 \mu \mathrm{s})$ absorption band (Figure 6f) at $520 \mathrm{~nm}$ which is identified to the $T_{1}$ to $T_{2}$ and higher triplet state $T_{n}$ absorption of TPA-DBPrz, 
which fully proves the theoretically predicted $\Delta E_{\mathrm{T}_{1} \mathrm{~T}_{2}}$ of $1.68 \mathrm{eV}$. These results confirm that the theoretically designed TPA-DBPrz possesses large $\Delta E_{\mathrm{T}_{1} \mathrm{~T}_{2}}$, potentially important for HLCT and SF application.

(a)

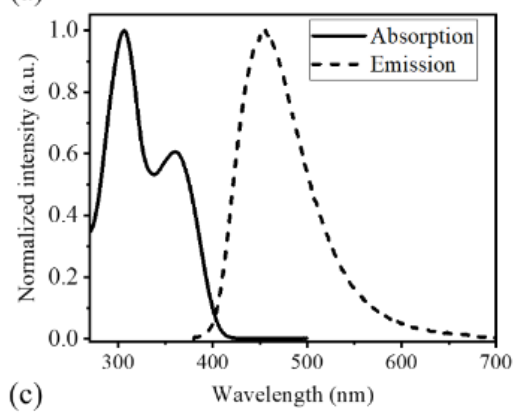

(c)

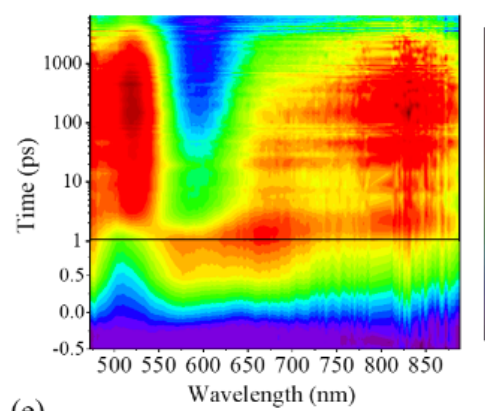

(e)



(b)

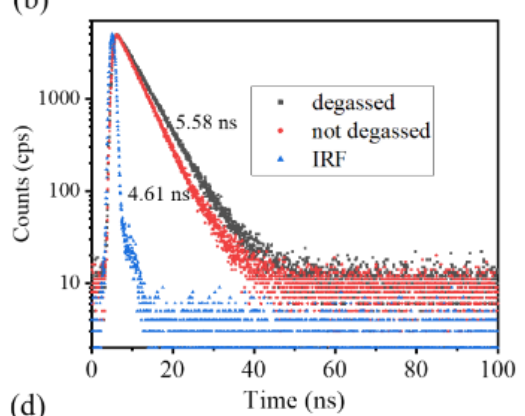

(d)
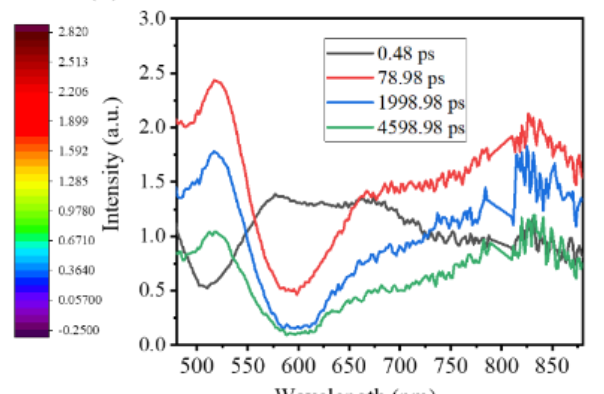

(f)

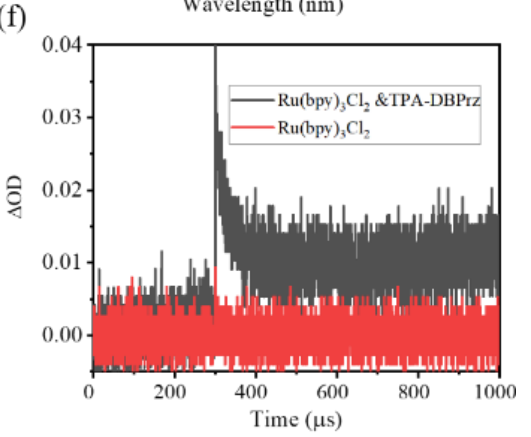

Figure 6. (a) Normalized UV-vis and PL spectra in DCM solution; (b) The PL decays of degassed and not degassed TPA-DBPrz in dilute DCM solutions; (c) and (d) fs-TA spectra and corresponding dynamics curves of TPA-DBPrz in the DCM solution $(10 \mu \mathrm{M})$; (e) ns-TA spectra of $\mathrm{Ru}(\mathrm{bpy})_{3} \mathrm{Cl}_{2} \& \mathrm{TPA}-\mathrm{DBPrz}$ solution at different time delays, $\mathrm{Ru}(\mathrm{bpy})_{3} \mathrm{Cl}_{2}(20 \mu \mathrm{M})$, TPADBPrz $(1 \mathrm{mM})$; (f) ns-TA measurement of $\mathrm{Ru}(\mathrm{bpy})_{3} \mathrm{Cl}_{2}(20 \mathrm{uM})$ and $\mathrm{Ru}(\mathrm{bpy})_{3} \mathrm{Cl}_{2}(20 \mathrm{uM})$ \&TPA-DBPrz $(1 \mathrm{mM})$ in DCM monitored at $520 \mathrm{~nm}$.

\section{Conclusion}

To conclude, we propose a molecular design strategy to obtain low $\mathrm{T}_{1}$ and large $\Delta \boldsymbol{E}_{\mathbf{T}_{\mathbf{1}} \mathbf{T}_{\mathbf{2}}}$ compounds which are of potential application in SF and hot exciton materials. We first investigate the low-lying excited state structures for a typical five-membered rings with 
different degree of conjugation using the state-of-the-art quantum chemistry approaches. It is found that the partly conjugated five-membered rings are expected to be good triplet-stabilized candidates because of elongated double bond (by 0.130 0.184 Angstrom) and high aromaticity in $\mathrm{T}_{1}$.

Then, we choose pyrazoline ring as a bridge and design 25 molecules of donor-bridge-acceptor (D-B-A) type through substituting donors and acceptor at different site positions. The calculated results indicate that $T_{1}$ is a LE state originating from pyrazoline ring, which maintain the ultralow $E\left(\mathrm{~T}_{1}\right)$ (very close to that of single pyrazoline ring, ca. $1.50 \mathrm{eV}$ ), while $\mathrm{T}_{2}$ is a LE state that mainly stems from either acceptor or donor moiety, generating high $E\left(\mathrm{~T}_{2}\right)$. Thus, the wide energy gap between $T_{1}$ and $T_{2}$ is produced in these molecules.

Finally, we synthesize a designed TPA-DBPrz molecule and investigate its photophysical properties by theoretical calculations and experimental measurements. The measured PL of TPA-DBPrz exhibits a blue emission and 90\% PLQY in DCM solution. The fs-TA spectra of TPA-DBPrz in DCM and the ns-TA spectra of TPA-DBPrz\&Ru(bpy) ${ }_{3} \mathrm{Cl}_{2}$ in DCM both show the absorption from $\mathrm{T}_{1}$ to $\mathrm{T}_{2}$ at $820 \mathrm{~nm}(1.51 \mathrm{eV})$, which fully proves the theoretically predicted $\Delta \boldsymbol{E}_{\mathrm{T}_{1} \mathrm{~T}_{2}}$ of $1.68 \mathrm{eV}$.

In summary, using reliable quantum chemistry methods, we have successfully identified fivemembered rings which can naturally stabilize triplet state, based on which we have designed 25 compounds that all exhibit ultralow $E\left(\mathrm{~T}_{1}\right)$ and ultra-large $\Delta \boldsymbol{E}_{\mathbf{T}_{\mathbf{1}} \mathbf{T}_{\mathbf{2}}}$ and thus serve as promising candidates for hot exciton and SF materials. This work will provide a new route and a number of novel chemical moieties for designing high-performance hot exciton and SF materials in practice.

\section{Acknowledgements}

This work was supported by the National Natural Science Foundation of China, Grant Nos. 21788102, 21973099 and 22003030, as well as by the Ministry of Science and Technology of China through the National Key R\&D Plan, Grant No. 2017YFA0204501 and 
2020YFB0204802. QO is also funded by China Postdoctoral Science Foundation Grant No. $2020 \mathrm{M} 670280$.

\section{References}

[1] a) C. W. Tang, S. A. VanSlyke, Appl. Phys. Lett 1987, 51, 913; b) S. Reineke, F. Lindner, G. Schwartz, N. Seidler, K. Walzer, B. Lussem, K. Leo, Nature 2009, 459, 234; c) Y. Sun, N. C. Giebink, H. Kanno, B. Ma, M. E. Thompson, S. R. Forrest, Nature 2006, 440, 908; d) R. C. Evans, P. Douglas, C. J. Winscom, Coordin Chem Rev 2006, 250, 2093.

[2] Z. Shuai, R. J. Silbey, and J. L. Brédas, Phy. Rev. Lett. 2000.

[3] a) H. Uoyama, K. Goushi, K. Shizu, H. Nomura, C. Adachi, Nature 2012, 492, 234; b) A. Endo, M. Ogasawara, A. Takahashi, D. Yokoyama, Y. Kato, C. Adachi, Adv Mater 2009, 21, 4802.

[4] H. Kaji, H. Suzuki, T. Fukushima, K. Shizu, K. Suzuki, S. Kubo, T. Komino, H. Oiwa, F. Suzuki, A. Wakamiya, Y. Murata, C. Adachi, Nat Commun 2015, 6, 8476.

[5] Y. Pan, W. Li, S. Zhang, L. Yao, C. Gu, H. Xu, B. Yang, Y. Ma, Adv Opt Mater 2014, 2, 510 .

[6] D. N. Congreve, J. Lee, N. J. Thompson, E. Hontz, S. R. Yost, P. D. Reusswig, M. E. Bahlke, S. Reineke, T. Van Voorhis, M. A. Baldo, Science 2013, 340, 334.

[7] R. Nagata, H. Nakanotani, W. J. Potscavage, Jr., C. Adachi, Adv Mater 2018, 30, 1801484.

[8] J. M. Millicent B. Smith Chem. Rev. 2010, 110, 6891.

[9] A. Akdag, Z. Havlas, J. Michl, J Am Chem Soc 2012, 134, 14624.

[10] N. C. Baird, J Am Chem Soc 1972, 94, 4941.

[11] Y. Xie, T. Zhang, Z. Li, Q. Peng, Y. Yi, Z. Shuai, Chem Asian J 2015, 10, 2154.

[12] a) H. Ottosson, Nat Chem 2012, 4, 969; b) K. J. Fallon, P. Budden, E. Salvadori, A. M. Ganose, C. N. Savory, L. Eyre, S. Dowland, Q. Ai, S. Goodlett, C. Risko, D. O. Scanlon, C. W. M. Kay, A. Rao, R. H. Friend, A. J. Musser, H. Bronstein, J Am Chem Soc 2019, $141,13867$.

[13] K. H. Daniel Geuenich, Felix Kohler, and Rainer Herges, Chem. Rev. 2005, 105, 3758.

[14] V. Cherpak, P. Stakhira, S. Khomyak, D. Volynyuk, Z. Hotra, L. Voznyak, G. Dovbeshko, O. Fesenko, V. Sorokin, A. Rybalochka, O. Oliynyk, Opt Mater. 2011, 33, 1727.

[15] C. J. Fahrni, L. Yang, D. G. VanDerveer, J Am Chem Soc 2003, 125, 3799.

[16] S. L. Zhu, Y. Wu, C. J. Liu, C. Y. Wei, J. C. Tao, H. M. Liu, Eur J Med Chem 2013, 65, 70 .

[17] Z. Liu, T. Lu, Q. Chen, Carbon 2020, 165, 461.

[18] Y. Xu, X. Liang, X. Zhou, P. Yuan, J. Zhou, C. Wang, B. Li, D. Hu, X. Qiao, X. Jiang, L. Liu, S. J. Su, D. Ma, Y. Ma, Adv Mater 2019, 31, 1807388.

[19] K. Xu, J. Zhao, E. G. Moore, Photochem Photobiol Sci 2016, 15, 995.

\section{Supporting Information}




\section{A Facile Strategy to Achieve Large Triplet Gap Based on Excited-State Aromaticity- tunable Five-memebered Ring}

Qi Sun, Yuanyuan Cui, Yishi Wu, Can Gao, Qi Ou, Deping Hu, Lu Wang, Yue Wang, Huanli Dong, Qian Peng*, and Zhigang Shuai*

\section{Computational Methods}

Firstly, we performed high level calculations using OpenMolcas package ${ }^{[1]}$ to calculate the excitation energies of the six five-membered rings at the $T_{1}$ geometry in Scheme 1.

Considering accuracy and the cost of calculation, we chose SA4-CASSCF $(10,10)$ to optimized the $\mathrm{T}_{1}$-geometry and MS4-CASPT2 $(10,10)$ to complete the excitation energies. TDDFT with Tamm-Dancoff approximation (TDA) can improve the accuracy of the calculated energy of triplet excited states. ${ }^{[2]}$ Brédas et al. have been used these methods to successfully calculated $\Delta E_{\mathrm{ST}}$ and $E\left(\mathrm{~S}_{1}\right)$ of some typical TADF molecules. ${ }^{[3]}$ We use the same method to calculate the pyrazoline derivatives. The ground state and excited state geometries were optimized at B3LYP/6-31G(d) and CAM-B3LYP/6-31G(d) level respectively. The excitation energies were calculated via optimally turned LC- $\omega$ PBE (LC- $\omega$ PBE*) with 6$31 \mathrm{G}(\mathrm{d})$ basis set. The value of $\omega$ for each molecule is in the Table S6. In order to consider solvent effect, all the calculations were carrying out using the polarizable continuum model $(\mathrm{PCM})^{[4]}$, the solvent is toluene in the whole calculations. Anisotropy of the induced current density (AICD) calculations were carried out at the B3LYP/6-31+G(d) level. All of the above calculations were conducted using the Gaussian 16 package $^{[5]}$. Hole-electron analysis ${ }^{[6]}$ and NTOs were conducted utilizing Multiwfn. ${ }^{[7]}$

\section{The synthesis of compound TPA-DBPrz}

2.1 The synthesis of (E)-3-(4-(diphenylamino)phenyl)-1-phenylprop-2-en-1-one (m3): 4(N,N-diphenylamino)benzaldehyde (m1) $8.2 \mathrm{~g}(0.03 \mathrm{~mol})$ and acetophenone $3.844(\mathbf{m} 2)$ $(0.033 \mathrm{~mol})$ were mixed into a $100 \mathrm{ml}$ round bottom flask with absolute alcohol $(30 \mathrm{~mL})$. The mixture was stirred at room temperature as well as $\mathrm{PH}=10$ environment for $8 \mathrm{~h}$ and was filtered directly. After washing by alcohol and drying, $\mathbf{m} \mathbf{3}$ was obtained as orange powder $(8.2 \mathrm{~g})$.

2.2 The synthesis of TPA-DBPrz: Phenylhydrazine $(\mathbf{m 4})(10 \mathrm{ml})$ was added slowly to acetic acid $(30 \mathrm{ml})$ and stirred for ten minutes at room temperature, then $\mathbf{m 3}(0.022 \mathrm{~mol})$ was added. The mixture was refluxed under nitrogen for $12 \mathrm{~h}$. Then it was cooled to room temperature and poured into ice water. After filtering, the crude product was washed by alcohol and dried. The solid was purified by column chromatography (silica gel, dichloromethane:petroleum ether $=3: 1$, volume ratio). 




Scheme S1. Synthetic route to compound TPA-DBPrz.

\subsection{The ${ }^{1} \mathrm{H}$ NMR and ${ }^{13} \mathrm{C}$ NMR spectra:}

The ${ }^{1} \mathrm{H}$ NMR and ${ }^{13} \mathrm{C}$ NMR spectra were recorded using a Bruker ADVANCE 400 NMR Spectrometer. All NMR spectra, if not otherwise specified, were measured at $25^{\circ} \mathrm{C}$ and calibrated using the residual solvent signals. Elemental analysis was carried out on Flash EA 1112 Elemental Analyzer. The mass spectrum was acquired using a Bruker MOLDI-TOF instrument.

${ }^{1} \mathrm{H}$ NMR (400 MHz, THF-d8) $\delta 7.76-7.70$ (m, 2H), 7.34 (dd, J = 8.3, 6.6 Hz, 2H), $7.30-$ $7.25(\mathrm{~m}, 1 \mathrm{H}), 7.19(\mathrm{t}, \mathrm{J}=8.0 \mathrm{~Hz}, 6 \mathrm{H}), 7.13-7.06(\mathrm{~m}, 4 \mathrm{H}), 7.03-6.92(\mathrm{~m}, 8 \mathrm{H}), 6.69(\mathrm{tt}, \mathrm{J}=$ $6.5,2.0 \mathrm{~Hz}, 1 \mathrm{H}), 5.29$ (dd, J = 12.3, $7.0 \mathrm{~Hz}, 1 \mathrm{H}), 3.86(\mathrm{dd}, \mathrm{J}=17.1,12.3 \mathrm{~Hz}, 1 \mathrm{H}), 3.13(\mathrm{dd}, \mathrm{J}$ $=17.2,7.0 \mathrm{~Hz}, 1 \mathrm{H})$. MALDI: calculated 465.21999, found: 465.21994. Elemental analysis for $\mathrm{C}_{33} \mathrm{H}_{27} \mathrm{~N}_{3}: \mathrm{C}, 85.13 \%$; H, 5.85\%; N, 9.03\%. Found: C, 85.12\%; H, 5.83\%; N, 9.02\%.

\section{Spectral characterization}

3.1 UV-vis spectra The absorption spectra in solution were recorded by a Jasco V-570 spectrometer. Photoluminescence spectra of solution were recorded on a Jasco FP-6600 spectrophotometer. Absolute photoluminescence quantum yield was measured on a Jasco FP6600 spectrophotometer equipped with an integrating sphere. Fluorescence decay measurements of the emitters were acquired in DCM solutions on a time-correlated single photon counting setup with excitation using a $390 \mathrm{~nm}$ laser. The degassed sample was bubbled under nitrogen for 20 minutes before measurement.

3.2 Femtosecond Transient Absorption Spectroscopy. A femtosecond laser system (Pharos, Light Conversion) delivered laser pulses at $1030 \mathrm{~nm}(180 \mathrm{fs}, 6 \mathrm{kHz})$, which were then divided into two components by using a 9:1 beam splitter. The major component was sent to an optical parametric amplifier (Orpheus, Light Conversion) to generate the pump pulses $(420 \mathrm{~nm}, 6 \mathrm{kHz})$. The minor component was further attenuated and focused into a 3$\mathrm{mm}$ sapphire plate to generate the probe pulses. Both the pump and probe pulses were guided into a Harppia spectrometer and time resolved spectral data were recorded. A short-pass filter was inserted into the probe beam to cut off the fundamental light of $1030 \mathrm{~nm}$. The time delay between the pump and probe beams were regulated through a computer-controlled motorized translation stage in the probe beam. The temporal resolution between the pump and the probe pulses was determined to be $\sim 200 \mathrm{fs}$ (FWHM). The transmitted light was detected by a CMOS linear image sensor. The excitation pulsed energy was $\sim 60 \mathrm{~nJ} / \mathrm{pulse}$ as measured at the sample site. Analysis of the kinetic traces derived from time-resolved spectra was performed using nonlinear least-square fitting to a general sum-of-exponentials function after deconvolution of instrument response function (IRF). All the spectroscopic measurements were carried out at room temperature. 
3.3 Nanosecond-to-microsecond transient absorption Experiments were performed using a commercial nanosecond laser flash photolysis spectrometer (LP980-KS, Edinburgh

Instruments Ltd., Livingston, UK) at ambient temperature. The pump laser pulse was obtained from Optical Parametric Oscillator (PrimoScan ULD400, Spectra-Physics) at $450 \mathrm{~nm}$, with the FWHM of no more than $10 \mathrm{~ns}$. The probe light was provided by a $150 \mathrm{~W}$ Pulsed xenon arc lamp. Sample solution in $1 \times 1 \mathrm{~cm}$ optical quartz cuvette was excited by the pump laser, afterwards the probe light from the xenon lamp passed through the sample in a right-angle configuration. The transmission probe light was measured either by a single PMT detector (Hamamatsu R928), using a Tektronix Model MDO3052 (100 MHz, 1.25 GSs-1) digital oscilloscope, at a specified wavelength for kinetic analysis or by a ICCD camera (DH320T, Andor) for spectral analysis. All the samples were bubbled under nitrogen for 20 minutes before measurement.

Table S1. The transitions of $S_{1}, T_{1}$ and $T_{2}$ states for the five-membered rings at $\mathrm{T}_{1}$-geometry at the level of MS4-CASPT2/cc-PVTZ and TDA-LC- $\omega$ PBE*/6-31G(d) with optimally-tuned $\omega^{*}$ values (Unit: Bohr ${ }^{-1}$ ) .

\begin{tabular}{|c|c|c|c|c|c|c|c|}
\hline \multirow{2}{*}{ Compound } & \multicolumn{3}{|c|}{ MS4-CASPT2/cc-PVTZ } & \multicolumn{3}{|c|}{ LC- $\omega$ PBE*/6-31G(d) } & \multirow{2}{*}{$\omega^{*}$} \\
\hline & $\mathrm{T}_{1}$ & $\mathrm{~T}_{2}$ & $\mathrm{~S}_{1}$ & $\mathrm{~T}_{1}$ & $\mathrm{~T}_{2}$ & $\mathrm{~S}_{1}$ & \\
\hline cyclopentene & $\mathrm{H}->\mathrm{L} 96 \%$ & H-4 -> L 94\% & H $>$ L $79 \%$ & H -> L $98 \%$ & $\begin{array}{l}\mathrm{H}-2 \text {-> L } 46 \% \\
\mathrm{H}-4 \text {-> L 38\% }\end{array}$ & $\mathrm{H} \rightarrow \mathrm{L} 90 \%$ & 0.2762 \\
\hline 3-pyrroline & $\mathrm{H}->\mathrm{L} 88 \%$ & H-1 -> L 87\% & $\begin{array}{c}\mathrm{H}->\mathrm{L}+132 \% \\
\mathrm{H}-1->\mathrm{L}+142 \%\end{array}$ & H -> L $89 \%$ & H-1 -> L 90\% & $\begin{array}{c}\mathrm{H}-1 \text {-> L } 78 \% \\
\text { H }>\text { L } 21 \%\end{array}$ & 0.2863 \\
\hline pyrazoline & H -> L $90 \%$ & $\begin{array}{l}\text { H-1 }>\text { L } 39 \% \\
\text { H-3 }>\text { L 51\% }\end{array}$ & $\mathrm{H}->\mathrm{L} 82 \%$ & H -> L $96 \%$ & H-1 -> L 98\% & H $>$ L $90 \%$ & 0.3422 \\
\hline pyrazole & $\begin{array}{c}\text { H -> L 38\% } \\
\text { H-1 -> L 48\% }\end{array}$ & $\begin{array}{c}\text { H -> L 29\% } \\
\text { H-1 >> L 34\% }\end{array}$ & $\begin{array}{l}\text { H-2 -> L } 15 \% \\
\text { H-1 -> L 28\% }\end{array}$ & H -> L 97\% & H-1 -> L 95\% & $\begin{array}{l}\mathrm{H}-2 \rightarrow>\mathrm{L} 76 \% \\
\mathrm{H}-1 \rightarrow \mathrm{L} 17 \%\end{array}$ & 0.3400 \\
\hline imidazole & $\mathrm{H}->\mathrm{L}+179 \%$ & $\begin{array}{c}\mathrm{H}->\mathrm{L}+446 \% \\
\mathrm{H}-1 \text {-> L+1 } 33 \%\end{array}$ & $\begin{array}{c}\mathrm{H}->\mathrm{L}+148 \% \\
\mathrm{H}-1 \text {-> L+1 } 14 \%\end{array}$ & H -> L $98 \%$ & H-1 -> L $92 \%$ & H $>$ L $97 \%$ & 0.3035 \\
\hline pyrrole & H -> L+1 87\% & $\begin{array}{c}\mathrm{H}->\mathrm{L}+335 \% \\
\mathrm{H}-1 \text {-> L+1 } 47 \%\end{array}$ & $\begin{array}{c}\mathrm{H}->\mathrm{L}+230 \% \\
\mathrm{H}-1 \text {-> L+1 } 38 \%\end{array}$ & H -> L $98 \%$ & $\begin{array}{c}\mathrm{H}-1 \text {-> L } 54 \% \\
\text { H } \rightarrow \text { L } 46 \%\end{array}$ & H -> L 98\% & 0.3020 \\
\hline
\end{tabular}

Table S2. Vertical excitation energies (Unit: $\mathrm{eV}$ ) of the five-membered rings at $\mathrm{T}_{1}$-geometry at the level of TDA-LC- $\omega$ PBE*/6-31G(d).

\begin{tabular}{cccccc}
\hline Compound & $E\left(\mathrm{~T}_{1}\right)$ & $E\left(\mathrm{~T}_{2}\right)$ & $E\left(\mathrm{~S}_{1}\right)$ & $2 E\left(\mathrm{~T}_{1}\right)$ & $\Delta E_{\mathrm{T}_{1} \mathrm{~T}_{2}}$ \\
\hline cyclopentene & 0.41 & 5.32 & 3.88 & 0.82 & 4.91 \\
3-pyrroline & 0.74 & 3.46 & 3.49 & 1.48 & 2.72 \\
pyrazoline & 1.43 & 4.56 & 4.48 & 2.86 & 3.13 \\
pyrazole & 2.73 & 4.50 & 5.64 & 5.46 & 1.77 \\
imidazole & 3.02 & 5.16 & 5.93 & 6.04 & 2.14 \\
pyrrole & 2.94 & 5.18 & 5.96 & 5.88 & 2.24 \\
\hline
\end{tabular}

Table S3. Optimally-tuned $\omega^{*}$ values for the LC- $\omega$ PBE functional and vertical excitation energies at $\mathrm{T}_{1}$ geometry of compound pyrazolinea-pyrazolinec at the level of TDA-LC- $\omega$ PBE*/6-31G(d) (Unit: $\mathrm{eV})$.

\begin{tabular}{lcccc}
\hline Compound & $\omega^{*}$ & $E\left(\mathrm{~T}_{1}\right)$ & $E\left(\mathrm{~T}_{2}\right)$ & $E\left(\mathrm{~S}_{1}\right)$ \\
\hline pyrazolinea & 0.2303 & 1.34 & 3.94 & 3.86 \\
pyrazolineb & 0.2386 & 1.70 & 3.82 & 4.03 \\
pyrazolinec & 0.2375 & 1.66 & 3.84 & 3.90 \\
\hline
\end{tabular}

Table S4. $E_{\text {Hомо }}$ and $E_{\mathrm{LUmo}}$ of the donors and acceptors investigated in this work calculated at the level of B3LYP/6-31G* (Unit: eV).

\begin{tabular}{ccc}
\hline Compound & $E_{\text {HOMO }}$ & $E_{\text {LUMO }}$ \\
\hline TP & -6.33 & -0.21 \\
Cz & -5.44 & -0.64 \\
PTZ & -4.76 & -0.44 \\
\hline
\end{tabular}




\begin{tabular}{ccc}
\hline PZ & -4.14 & -0.88 \\
FB & -6.62 & -0.24 \\
Py & -6.78 & -0.61 \\
BN & -7.26 & -1.41 \\
\hline
\end{tabular}

Table S5. Significantly changed bonds (Unit: $\AA$ ) of the investigated compounds in Scheme $1\left(L_{n}^{A}\right.$ means bond $L_{n}$ at A geometry)

\begin{tabular}{|c|c|c|c|c|c|c|c|c|c|}
\hline Compound & $L_{1}^{\mathrm{S}_{0}}$ & $L_{1}^{\mathrm{S}_{1}}$ & $L_{1}^{\mathrm{T}_{1}}$ & $L_{2}^{\mathrm{S}_{0}}$ & $L_{2}^{\mathrm{S}_{1}}$ & $L_{2}^{\mathrm{T}_{1}}$ & $L_{3}^{\mathrm{S}_{0}}$ & $L_{3}^{\mathrm{S}_{1}}$ & $L_{3}^{\mathrm{T}_{1}}$ \\
\hline 1 & 1.295 & 1.365 & 1.431 & 1.461 & 1.406 & 1.389 & 1.389 & 1.36 & 1.391 \\
\hline 2 & 1.296 & 1.36 & 1.428 & 1.462 & 1.412 & 1.391 & 1.382 & 1.332 & 1.367 \\
\hline 3 & 1.298 & 1.349 & 1.416 & 1.458 & 1.415 & 1.393 & 1.38 & 1.327 & 1.362 \\
\hline 4 & 1.300 & 1.347 & 1.414 & 1.455 & 1.412 & 1.392 & 1.398 & 1.348 & 1.389 \\
\hline 5 & 1.301 & 1.341 & 1.403 & 1.454 & 1.412 & 1.384 & 1.399 & 1.352 & 1.388 \\
\hline 6 & 1.353 & 1.348 & 1.42 & 1.458 & 1.412 & 1.392 & 1.391 & 1.347 & 1.387 \\
\hline 7 & 1.299 & 1.341 & 1.409 & 1.456 & 1.410 & 1.383 & 1.392 & 1.35 & 1.387 \\
\hline 8 & 1.297 & 1.334 & 1.418 & 1.461 & 1.423 & 1.391 & 1.393 & 1.345 & 1.382 \\
\hline 9 & 1.301 & 1.327 & 1.382 & 1.454 & 1.417 & 1.391 & 1.396 & 1.341 & 1.364 \\
\hline 10 & 1.296 & 1.364 & 1.431 & & & 1.390 & 1.462 & & 1.389 \\
\hline 11 & 1.293 & 1.380 & 1.447 & 1.521 & 1.512 & 1.516 & 1.467 & 1.403 & 1.386 \\
\hline 12 & 1.293 & 1.380 & 1.446 & 1.466 & 1.403 & 1.386 & 1.521 & 1.512 & 1.516 \\
\hline 13 & 1.293 & 1.382 & 1.440 & 1.471 & 1.403 & 1.390 & 1.517 & 1.517 & 1.521 \\
\hline 14 & 1.294 & 1.382 & 1.440 & 1.517 & 1.517 & 1.521 & 1.471 & 1.403 & 1.390 \\
\hline 15 & 1.283 & 1.384 & 1.447 & 1.398 & 1.362 & 1.390 & 1.518 & 1.514 & 1.513 \\
\hline 16 & 1.283 & 1.385 & 1.447 & 1.518 & 1.513 & 1.512 & 1.397 & 1.365 & 1.391 \\
\hline 17 & 1.282 & 1.362 & 1.453 & 1.520 & 1.506 & 1.516 & 1.402 & 1.350 & 1.394 \\
\hline 18 & 1.282 & 1.360 & 1.452 & 1.404 & 1.347 & 1.393 & 1.520 & 1.506 & 1.516 \\
\hline 19 & 1.296 & 1.366 & 1.430 & 1.464 & 1.409 & 1.391 & 1.393 & 1.361 & 1.391 \\
\hline 20 & 1.296 & 1.366 & 1.431 & 1.465 & 1.408 & 1.390 & 1.392 & 1.361 & 1.391 \\
\hline 21 & 1.296 & 1.365 & 1.430 & 1.464 & 1.411 & 1.391 & 1.395 & 1.362 & 1.392 \\
\hline 22 & 1.293 & 1.367 & 1.431 & 1.463 & 1.408 & 1.390 & 1.398 & 1.362 & 1.394 \\
\hline 23 & 1.294 & 1.366 & 1.431 & 1.462 & 1.408 & 1.390 & 1.396 & 1.362 & 1.393 \\
\hline 24 & 1.293 & 1.367 & 1.432 & 1.400 & 1.410 & 1.390 & 1.463 & 1.364 & 1.395 \\
\hline TPA-DBPrz & 1.294 & 1.346 & 1.431 & 1.463 & 1.423 & 1.390 & 1.397 & 1.344 & 1.394 \\
\hline
\end{tabular}

Table S6. Optimally-tuned $\omega^{*}$ values for the LC- $\omega$ PBE functional with $6-31 \mathrm{G}(\mathrm{d})$ basis sets, corresponding oscillator strengths $(f)$ of $\mathrm{S}_{1}$ state and vertical transition energies at $\mathrm{S}_{1}$-geometry (Unit: $\mathrm{eV})$.

\begin{tabular}{cccccc}
\hline Compound & $\omega^{*}$ & $\mathrm{f}$ & $E\left(\mathrm{~T}_{1}\right)$ & $E\left(\mathrm{~S}_{1}\right)$ & $E\left(\mathrm{~T}_{2}\right)$ \\
\hline $\mathbf{1}$ & 0.2032 & 1.067 & 1.86 & 3.27 & 3.66 \\
$\mathbf{2}$ & 0.2076 & 0.864 & 1.77 & 3.00 & 3.17 \\
$\mathbf{3}$ & 0.2084 & 0.789 & 1.70 & 2.87 & 3.20 \\
$\mathbf{4}$ & 0.1854 & 1.207 & 1.76 & 2.94 & 2.92 \\
$\mathbf{5}$ & 0.1904 & 1.460 & 1.67 & 2.78 & 2.93 \\
$\mathbf{6}$ & 0.1879 & 1.035 & 1.83 & 2.96 & 3.11 \\
\hline
\end{tabular}




\begin{tabular}{cccccc}
\hline $\mathbf{7}$ & 0.1829 & 1.248 & 1.73 & 2.80 & 3.03 \\
$\mathbf{8}$ & 0.1872 & 0.634 & 1.80 & 2.63 & 2.43 \\
$\mathbf{9}$ & 0.1871 & 0.822 & 1.53 & 2.30 & 2.42 \\
$\mathbf{1 0}$ & 0.2047 & 1.041 & 1.86 & 3.24 & 3.43 \\
$\mathbf{1 1}$ & 0.2447 & 0.270 & 2.30 & 3.67 & 3.48 \\
$\mathbf{1 2}$ & 0.2385 & 0.279 & 2.31 & 3.67 & 3.81 \\
$\mathbf{1 3}$ & 0.1941 & 0.098 & 1.87 & 2.66 & 3.63 \\
$\mathbf{1 4}$ & 0.2216 & 0.109 & 1.86 & 2.65 & 3.63 \\
$\mathbf{1 5}$ & 0.2429 & 0.675 & 1.82 & 3.94 & 3.83 \\
$\mathbf{1 6}$ & 0.2417 & 0.698 & 1.82 & 3.92 & 3.96 \\
$\mathbf{1 7}$ & 0.2398 & 0.658 & 1.82 & 3.83 & 3.98 \\
$\mathbf{1 8}$ & 0.2411 & 0.682 & 1.82 & 3.80 & 3.82 \\
$\mathbf{1 9}$ & 0.2007 & 0.917 & 1.83 & 3.20 & 3.65 \\
$\mathbf{2 0}$ & 0.1960 & 0.957 & 1.85 & 3.21 & 3.64 \\
$\mathbf{2 1}$ & 0.2010 & 0.798 & 1.81 & 3.15 & 3.65 \\
$\mathbf{2 2}$ & 0.2023 & 0.943 & 1.82 & 3.19 & 3.65 \\
$\mathbf{2 3}$ & 0.1977 & 0.976 & 1.82 & 3.18 & 3.65 \\
$\mathbf{2 4}$ & 0.2036 & 0.838 & 1.82 & 3.15 & 3.65 \\
TPA-DBPrz & 0.1802 & 0.894 & 1.80 & 3.12 & 3.32 \\
\hline
\end{tabular}
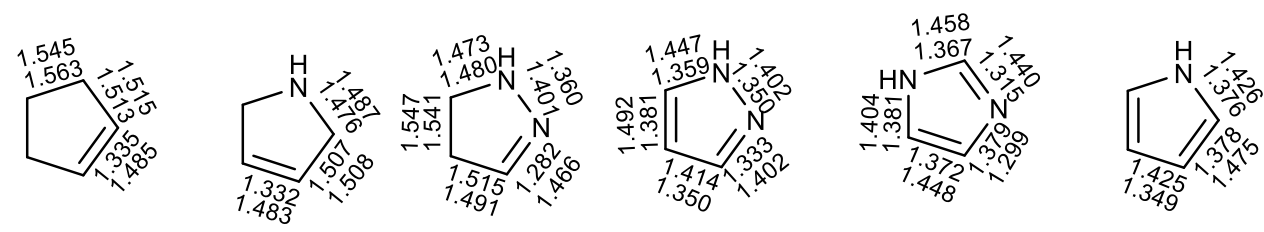

cyclopentene 3-pyrroline pyrazoline

imidazole

pyrrole

Figure S1. Bond lengths of cyclopentene-pyrrole at the level of B3LYP/6-31G* (Inside: $\mathrm{S}_{0}$ geometry; Outside: $\mathrm{T}_{1}$ geometry). 
(a)

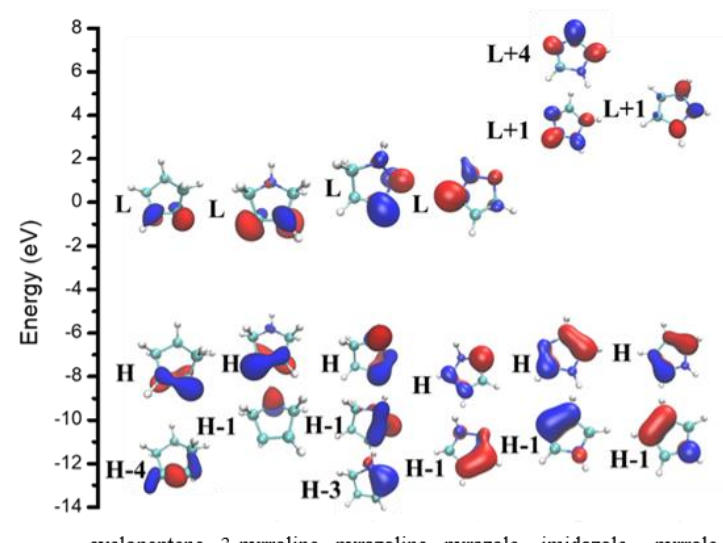

(b)

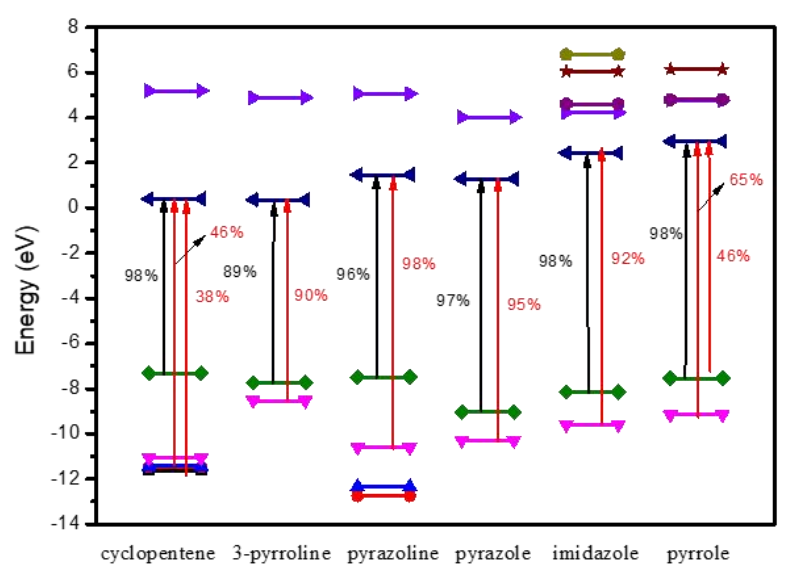

(c)

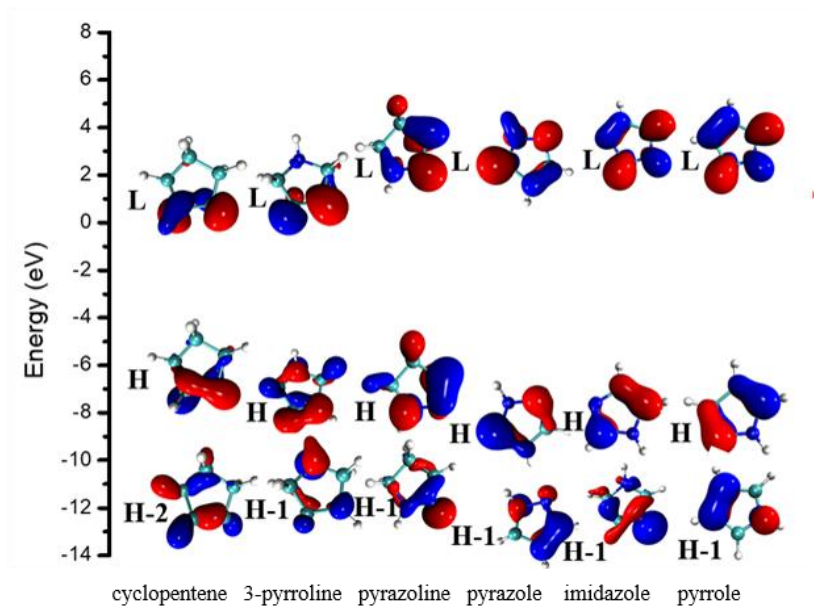

Figure S2. (a) The involved orbitals of the $\mathrm{T}_{1}$ and $\mathrm{T}_{2}$ state at the level of MS4-CASPT2/cc-PVTZ. (b) The main transitions of $\mathrm{T}_{1}$ (black) and $\mathrm{T}_{2}$ (red) state for the five-membered rings at $\mathrm{T}_{1}$-geometry at the level of TDA-LC- $\omega P B E * / 6-31 G(d)$ based on orbital energies calculated by LC- $\omega$ PBE*/6-31G(d) respectively. (c) The electronic charge of the involved orbitals of the $\mathrm{T}_{1}$ and $\mathrm{T}_{2}$ states at the level of LC- $\omega$ PBE*/6-31G(d). 
(a)
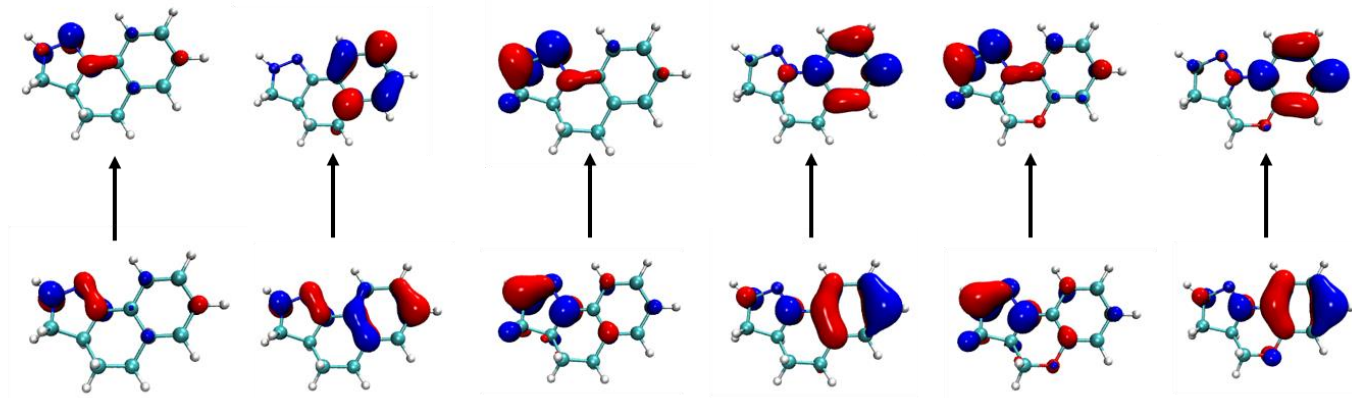

$\mathrm{T}_{1}$

$\mathrm{T}_{2}$


pyrazolinea

$\mathrm{T}_{1}$

$\mathrm{T}_{2}$

$\mathrm{T}_{1}$

$\mathrm{T}_{2}$

pyrazolineb

pyrazolinec

(b)
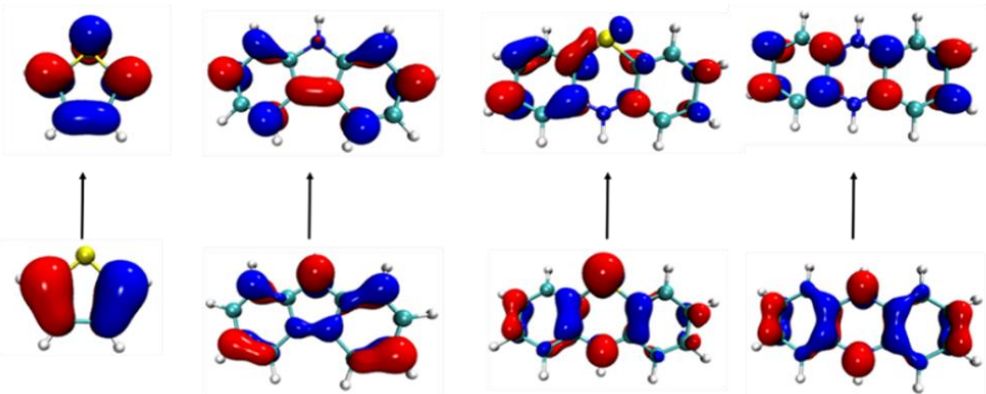

$\mathrm{TP}$

$\mathrm{Cz}$

PTZ

PZ

Figure S3. (a) NTOs of pyrazolinea, pyrazolineb and pyrazolinc at $T_{1}$ and $T_{2}$ states respectively at the level of TDA-LC- $\omega$ PBE*/6-31G(d). (b) The electronic charge of involved molecular orbitals in $\mathrm{T}_{1}$ state for TP, Cz, PTZ and PZ. 


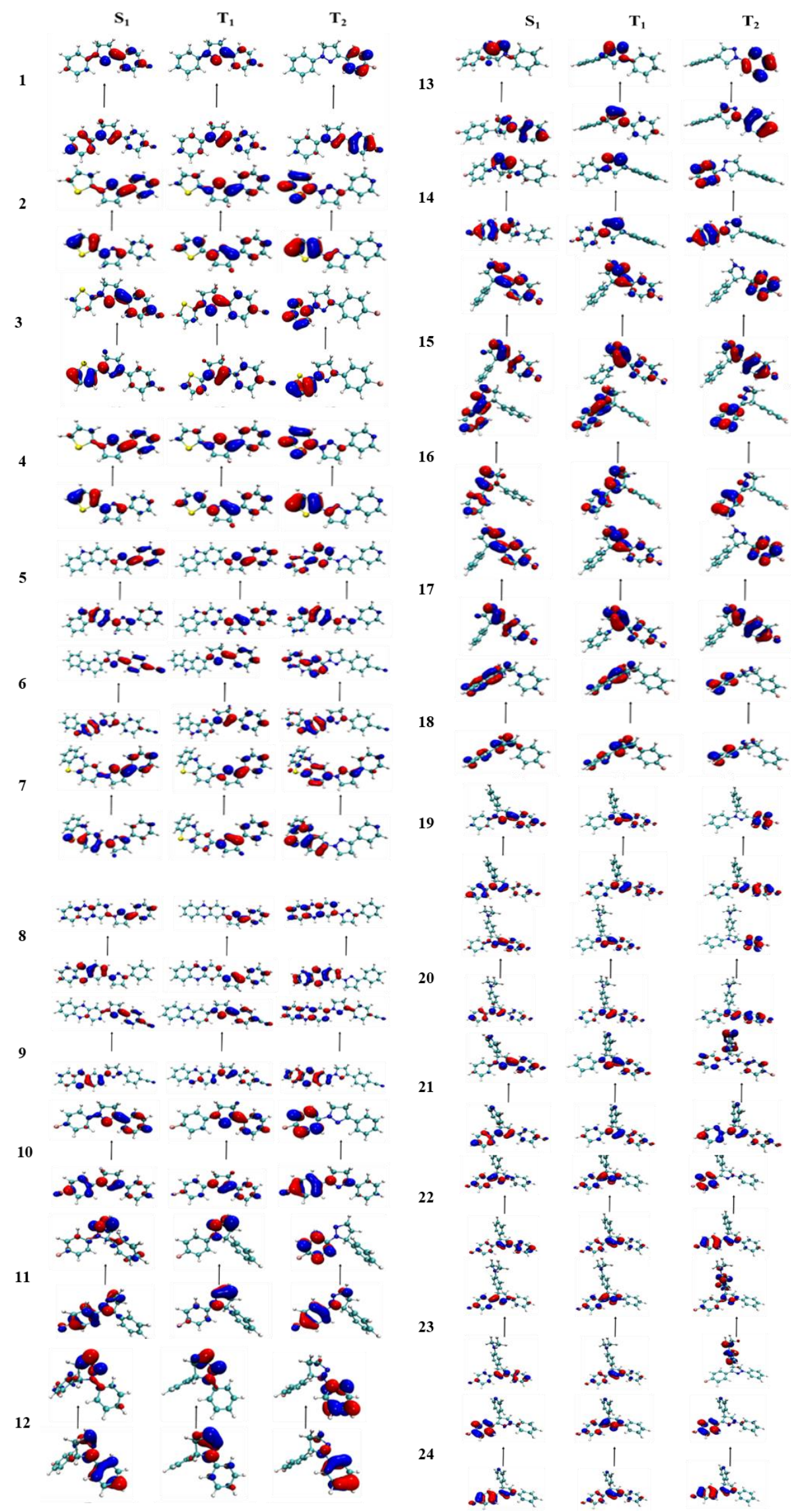

Figure S4. NTOs of the $S_{1}, T_{1}$ and $T_{2}$ states at the corresponding $S_{1^{-}}, T_{1^{-}}, T_{1}$-geometry respectively for compounds 1-24. 


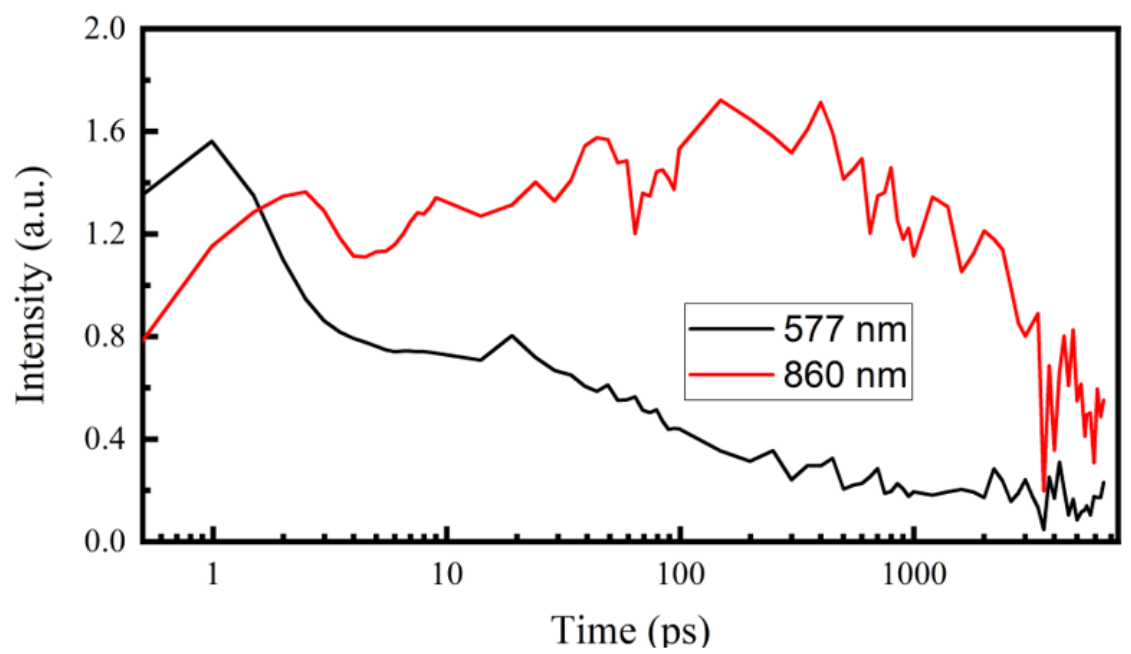

Figure S5. fs-TA dynamics curves of TPA-DBPrz in the DCM solution $(10 \mu \mathrm{M})$.

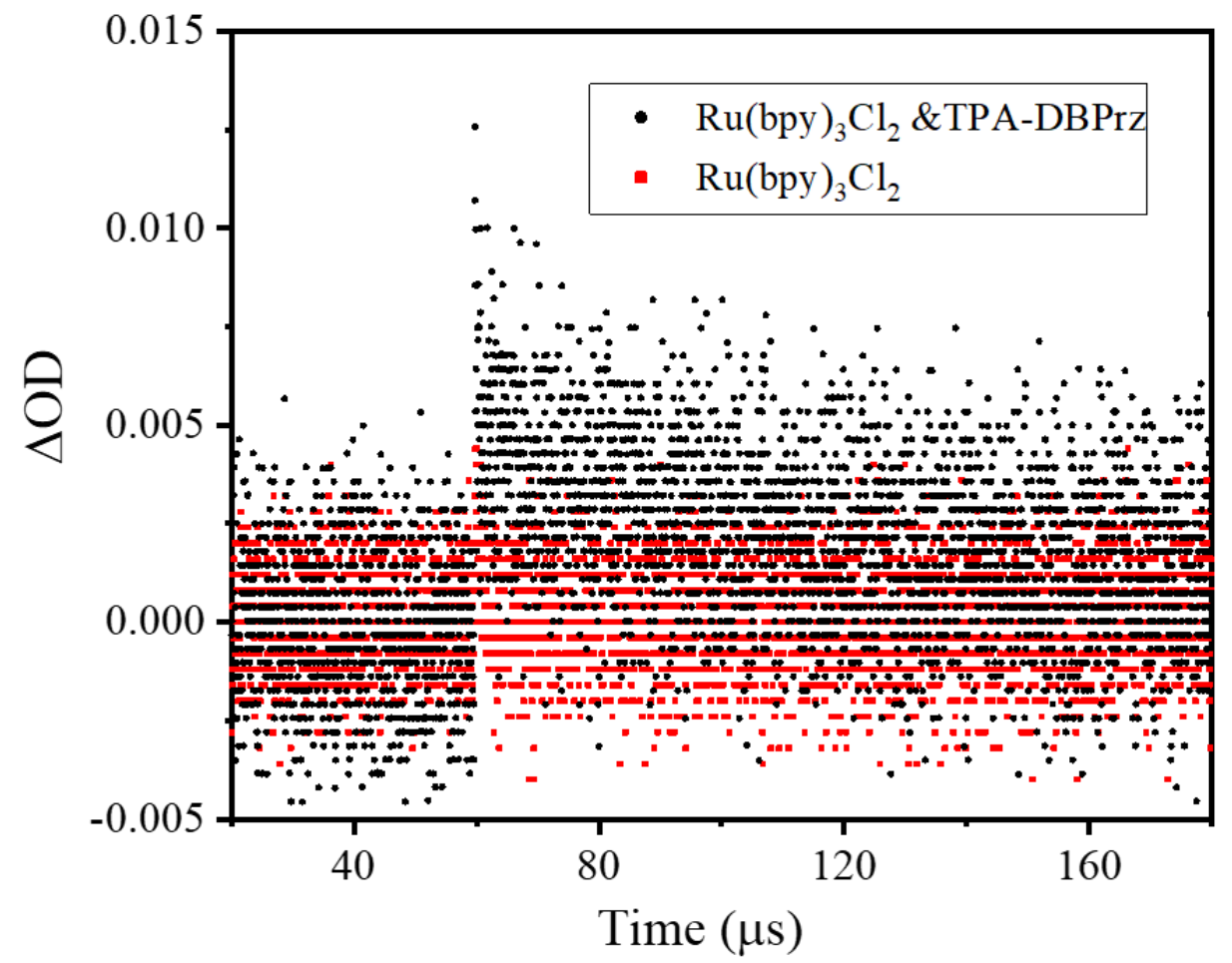

Figure S6. ns-TA measurement of $\mathrm{Ru}(\mathrm{bpy})_{3} \mathrm{Cl}_{2}(20 \mathrm{uM})$ and $\mathrm{Ru}(\mathrm{bpy})_{3} \mathrm{Cl}_{2}(20 \mathrm{uM}) \&$ TPA-DBPrz $(1$ $\mathrm{mM}$ ) in DCM monitored at $820 \mathrm{~nm}$. 


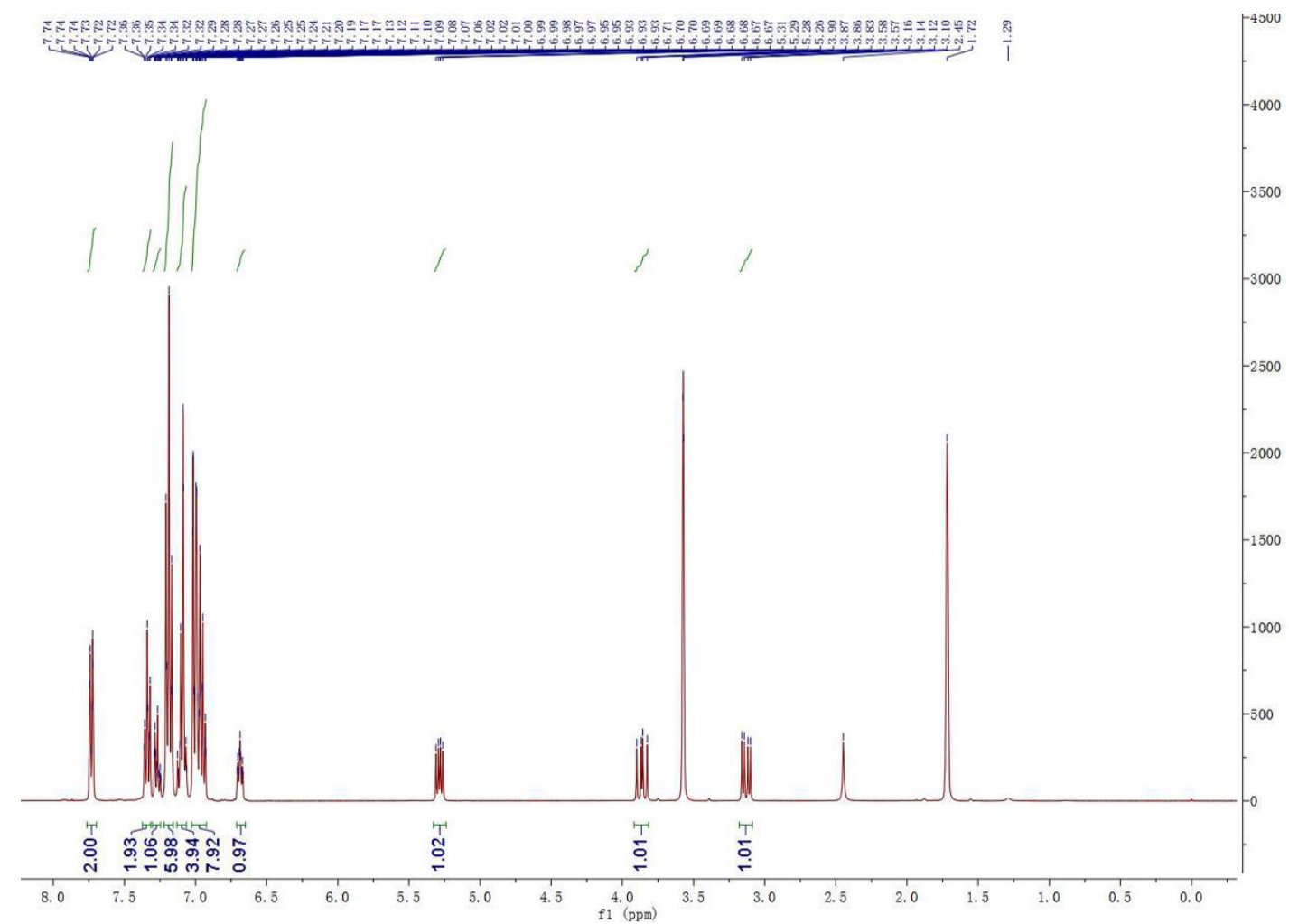

Figure S7. ${ }^{1} \mathrm{H}$ NMR (400 MHz, THF-d8) of compound TPA-DBPrz

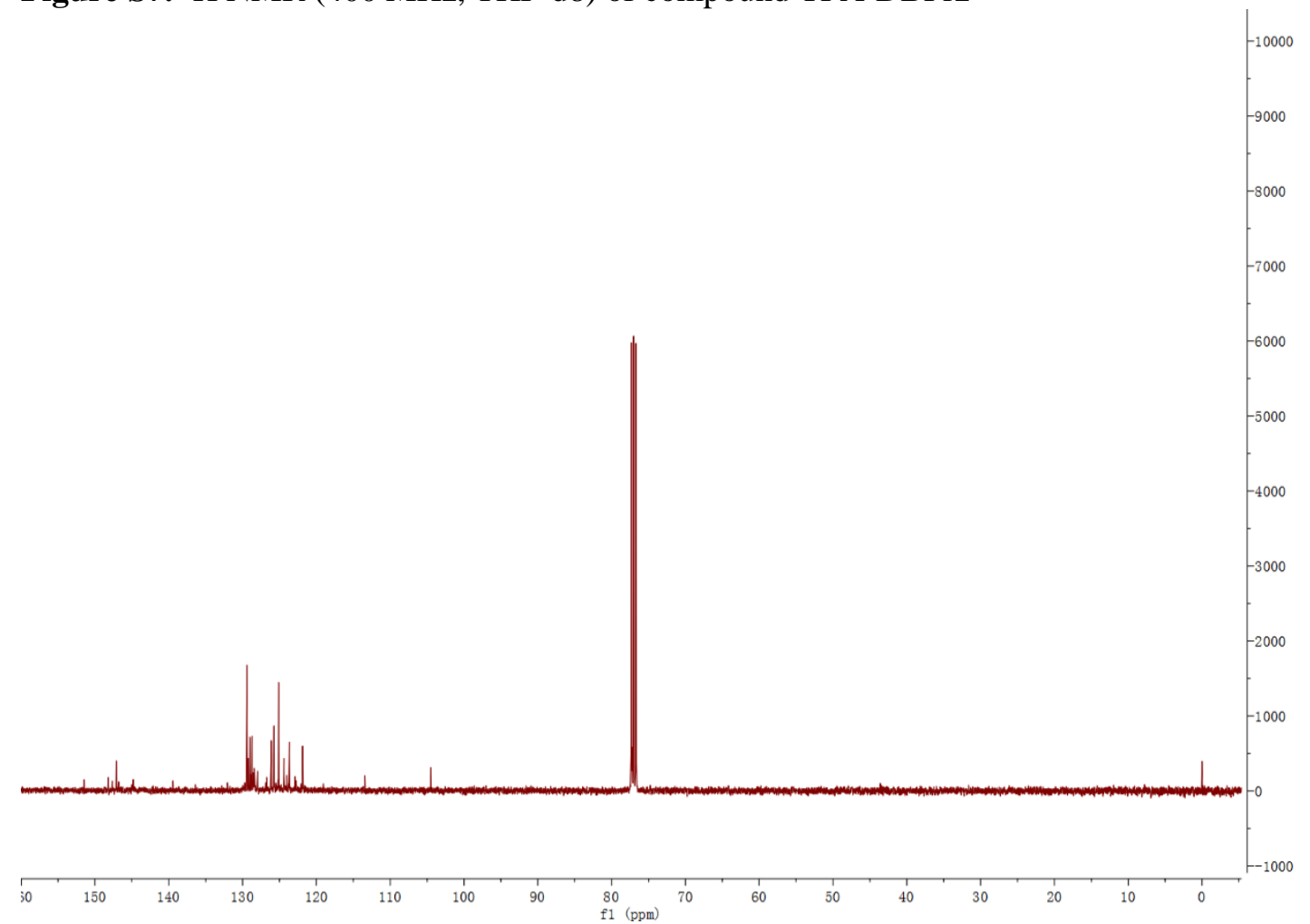

Figure S8. ${ }^{13} \mathrm{C}$ NMR (100 MHz, THF-d8) of compound TPA-DBPrz. 


\section{MALDI,P-P,20200918}

Analysis Info

Analysis Name D:IDatalMALDIL202010918IP-P_0_H14_000003.d

Method

MALDI_P_100-3000

Sample Name MURU-N-ESI

Comment

Acquisition Parameter

Acquisition Mode

Bros $\quad 800.0 \mathrm{~m} / \mathrm{z}$

Source Accumulation $0.001 \mathrm{sec}$

Ion Accumulation Time $0.100 \mathrm{sec}$
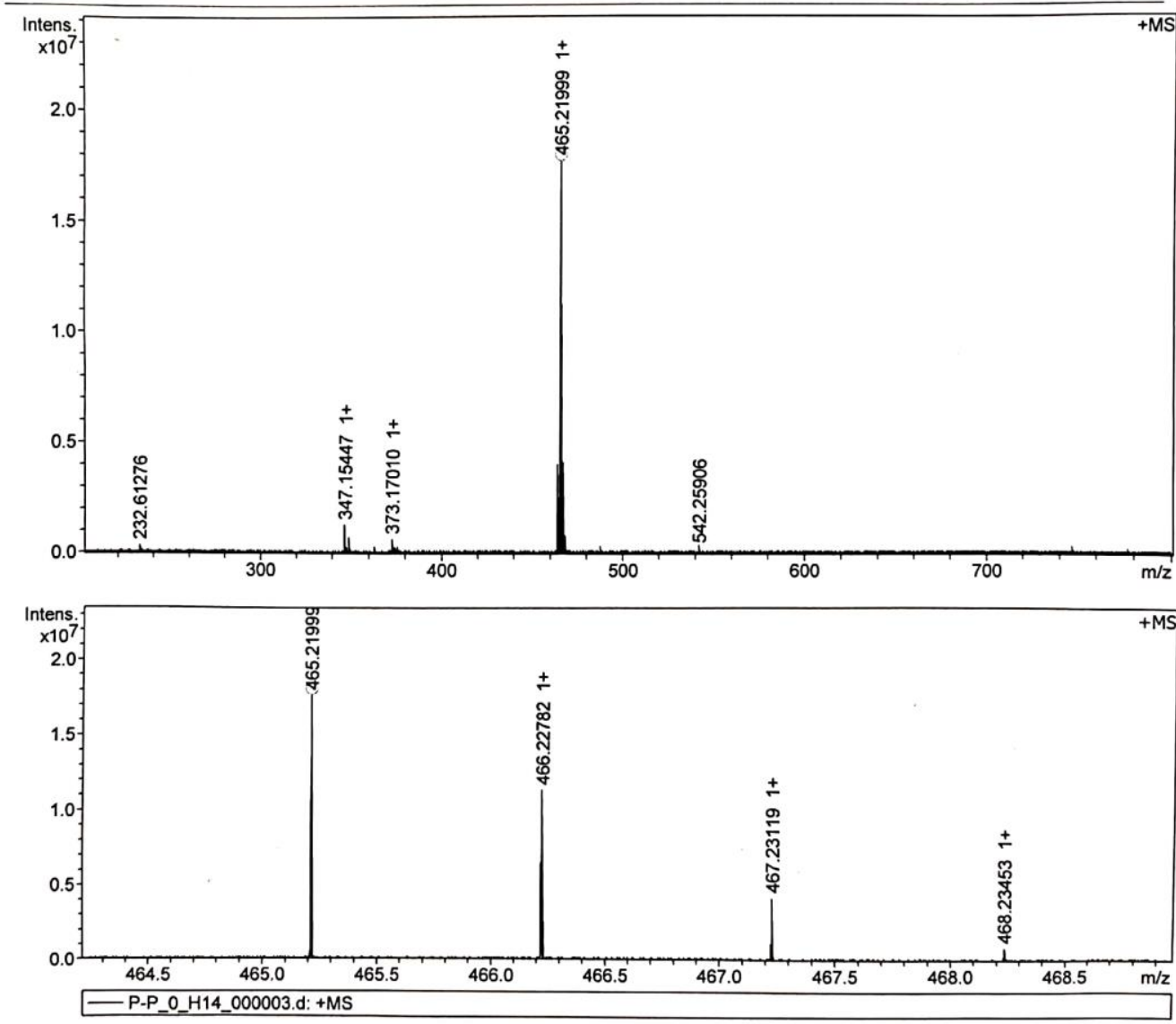

Meas. $\mathrm{m} / \mathrm{z}$ \# Ion Formula $465.219990 \quad 1 \quad$ C33H27N3

$\mathrm{m} / \mathrm{z}$ err [ppm] Mean err [ppm] mSigma rdb $\mathrm{e}^{-}$Conf $\mathrm{N}$-Rule
Acquisition Date 9/18/2020 6:13:04 PM

Operator

Instrument solariX
Calibration Date

Thu Sep 17 05:24:46

Acquired Scans No. of Cell Fills $\quad 1$. $22.6 \mathrm{lp}$ Laser Shot Frequency $\quad 0.020 \mathrm{sec}$ Data Acquisition Size No. of Laser Shots
2090152

Sine-Bell Multiplication

Figure S9. High resolution mass spectrometry of TPA-DBPrz. 




cyclopentene



3-pyrroline

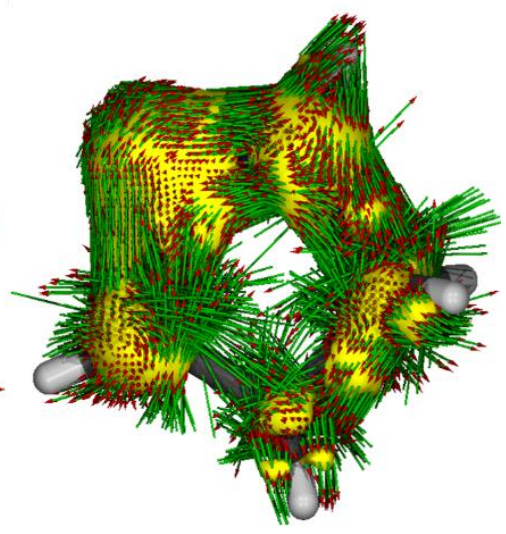

pyrazoline

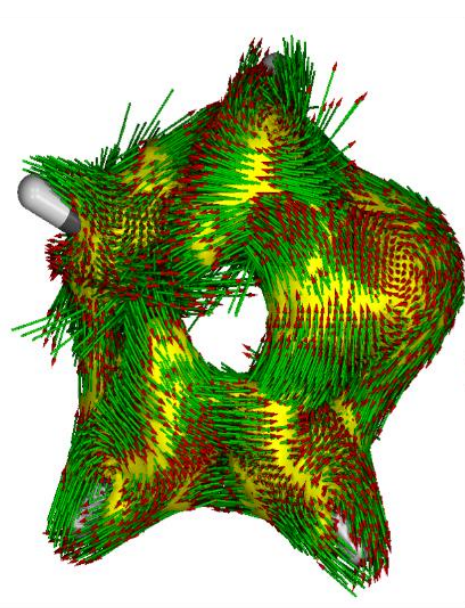

pyrazole

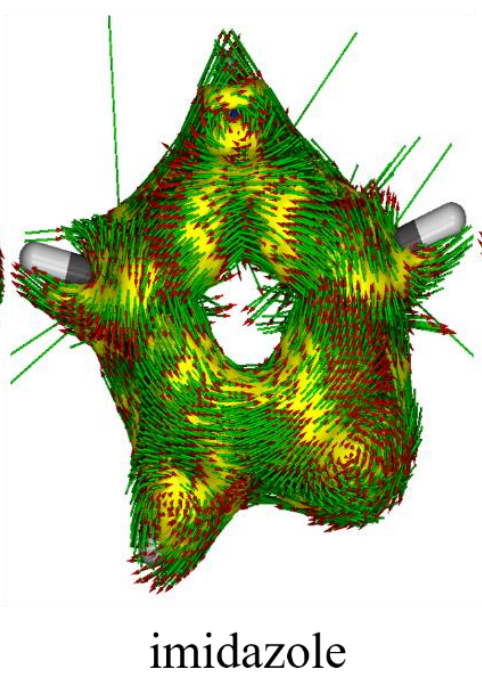

imidazole

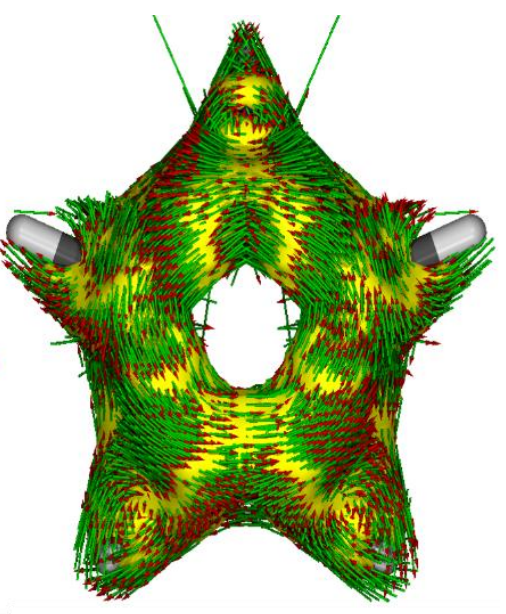

pyrrole

Figure S10. AICD plots of six five-numbered rings in the $\mathrm{T}_{1}$ state. The induced current density vectors are denoted by the arrows.

\section{Reference}

[1] F. Aquilante, J. Autschbach, R. K. Carlson, L. F. Chibotaru, M. G. Delcey, L. De Vico, I. Fdez Galvan, N. Ferre, L. M. Frutos, L. Gagliardi, M. Garavelli, A. Giussani, C. E. Hoyer, G. Li Manni, H. Lischka, D. Ma, P. A. Malmqvist, T. Muller, A. Nenov, M. Olivucci, T. B. Pedersen, D. Peng, F. Plasser, B. Pritchard, M. Reiher, I. Rivalta, I. Schapiro, J. Segarra-Marti, M. Stenrup, D. G. Truhlar, L. Ungur, A. Valentini, S. Vancoillie, V. Veryazov, V. P. Vysotskiy, O. Weingart, F. Zapata, R. Lindh, J Comput Chem 2016, 37, 506.

[2] M. J. Peach, M. J. Williamson, D. J. Tozer, J Chem Theory Comput 2011, 7, 3578.

[3] a) P. K. Samanta, D. Kim, V. Coropceanu, J. L. Bredas, J Am Chem Soc 2017, 139, 4042; b) H. Sun, C. Zhong, J. L. Bredas, J Chem Theory Comput 2015, 11, 3851.

[4] G. Scalmani, M. J. Frisch, J Chem Phys 2010, 132, 114110.

[5] M. J. Frisch, G. W. Trucks, H. B. Schlegel, G. E. Scuseria, M. A. Robb, J. R. Cheeseman, G. Scalmani, V. Barone, G. A. Petersson, H. Nakatsuji, X. Li, M. Caricato, A. V. Marenich, J. Bloino, B. G. Janesko, R. Gomperts, B. Mennucci, H. P. Hratchian, J. V. Ortiz, A. F. Izmaylov, J. L. Sonnenberg, Williams, F. Ding, F. Lipparini, F. Egidi, J. Goings, B. Peng, A. Petrone, T. Henderson, D. Ranasinghe, V. G. Zakrzewski, J. Gao, N. Rega, G. Zheng, W. Liang, M. Hada, M. Ehara, K. Toyota, 
R. Fukuda, J. Hasegawa, M. Ishida, T. Nakajima, Y. Honda, O. Kitao, H. Nakai, T. Vreven, K. Throssell, J. A. Montgomery Jr., J. E. Peralta, F. Ogliaro, M. J. Bearpark, J. J. Heyd, E. N. Brothers, K. N. Kudin, V. N. Staroverov, T. A. Keith, R. Kobayashi, J. Normand, K. Raghavachari, A. P. Rendell, J. C. Burant, S. S. Iyengar, J. Tomasi, M. Cossi, J. M. Millam, M. Klene, C. Adamo, R. Cammi, J. W. Ochterski, R. L. Martin, K. Morokuma, O. Farkas, J. B. Foresman, D. J. Fox, Wallingford, CT 2016.

[6] Z. Liu, T. Lu, Q. Chen, Carbon 2020, 165, 461.

[7] a) T. Lu, F. Chen, J Comput Chem 2012, 33, 580; b) Multiwfn Manual, version 3.6(dev), Section 3.21.1, available at http://sobereva.com/multiwfn (accessed Aug 30, 2018). 